\title{
Overview on Agent-Based Social Modelling and the use of Formal Languages
}

\author{
C. Montañola Sales, X. Rubio Campillo, J.M. Cela Espin \\ Computer Applications in Science \& Engineering, \\ Barcelona Supercomputing Center Barcelona, Spain \\ \{cristina.montanola, xavier.rubio, josem.cela\} @bsc.es \\ J. Casanovas Garcia \\ Departament d'Estadística i Investigació Operativa (EIO) \\ Universitat Politècnica de Catalunya (UPC) - BarcelonaTECH, Barcelona, Spain \\ josep.casanovas@upc.edu
}

\author{
A. Kaplan Marcusan \\ Cátedra de Transferencia del Conocimiento, Parc de Recerca UAB-Santander \\ Dept. Antropologia Social y Cultural, Universitat Autònoma de Barcelona, Barcelona, Spain \\ Adriana.Kaplan@uab.cat
}

\begin{abstract}
The use of agent-based modelling and simulation techniques in the social sciences has flourished in the recent decades. The main reason is that the object of study in these disciplines, human society present or past, is difficult to analyze through classical analytical techniques. Population dynamics and structures are inherently complex. Thus, other methodological techniques need to be found to more adequately study this field. In this context, agent-based modelling is encouraging the introduction of computer simulations to examine behavioural patterns in complex systems. Simulation provides a tool to artificially examine societies, where a big number of actors with decision capacity coexist and interact. However, formal modelling in these areas has not traditionally been used compared to other fields of science, specially in their use of formal languages during the modelling process. In this chapter we aim to revise the most relevant aspects on modelling in social sciences and to discuss the use formal languages by social scientists.
\end{abstract}

\section{Introduction}

Computer modelling and complex systems simulation have dominated the scientific debate over the last decade, providing important outcomes in biology, geology and life sciences, and resulting in the birth of entirely new disciplines (e.g. bioinformatics, geoinformatics, health informatics, etc..). In the social sciences, the number of groups currently developing research programs in this direction is increasing. The results are extremely promising since simulation technologies have the potential to become an essential tool in the field (G. Gilbert, 2008). 
However, some social scientists are sceptical about the idea of reproducing "inside" a computer population dynamics, because of the perceived complexity of social structures. This scepticism is understandable given the low number of projects that used this approach and the lack of experience of social scientists with these tools. Nevertheless, the research done in complexity science during recent years shows the way computer simulation can be applied to this field. Artificial intelligence portrays how the appropriate interconnection of very simple computational mechanisms is able to show extraordinary complex patterns, and access to distributed computing has become affordable. For this reason, agent-based simulation allows the implementation of experiments and studies that would not be viable otherwise (Pavon, Arroyo, Hassan, \& Sansores, 2008).

Even though research in social complex systems is increasing, the number of social research using computer simulation in this area is not very substantial, according to the survey conducted by (Leombruni \& Richiardi, 2006). Thus, efforts need to be made in order to give a boost in this multidisciplinary area of research, and provide tools suitable for this task. Collaboration among research groups becomes crucial, but the fact that social scientists and modellers use different languages is an issue that should be addressed in order to reach scientific advances. This is the reason why one of the main challenges of social simulation is to find a methodology capable of improving the communication channels between people related with the construction of the simulation model, who probably come from very different backgrounds. Only when there is a good communication between stakeholders simulation can be successful (Robinson \& Pidd, 1998).

Formal languages are one of the possible solutions and probably the most suitable one. Here when we say formal language or formalism we refer to a language that is not ambiguous and can describe the behaviour of a system. In that sense, a formal language can be mathematics or modelling languages such as Unified Modelling Language (UML), Petri Nets, Specification and Description Language (SDL) and those who are used as the basis for defining programming languages used in computer science. For instance, differential equations are used to describe the dynamic behaviour of complex systems in System Dynamics approach. The advantage of using formal languages is that they can explicitly describe the system to be modelled despite its complexity.

In that way, stakeholders could agree on how to define the simulation model, making the common work possible and helping in later stages of development such as verification and validation processes (Fonseca, 2008). However, social scientists and humanists usually are not trained on working with formalisms as in other disciplines of science. Moreover, there are no general conventions when modelling social processes.

The main question analysed in this chapter is how the use of formal languages can contribute to research in social fields. We aim to revise the most relevant aspects on modelling in social sciences. The remainder of this chapter is organised as follows. Section summarizes the current state of the art on the modelling process, in particular to these areas of research. In section components and needs of agent-based simulation models will be revised, and some applications of agent-based systems in different fields of humanities and social science will be shown. Finally, we will revise the characteristics of four different tools for social simulation studies in Section and we will discuss some validation practices applied to these areas in Section and some conclusions and remarks will be pointed out in Section .

\section{Modelling social systems}

Social sciences and humanities are concern with the study of human being and their world. Using methods of empirical data collection and scientific analysis, the social sciences study human 
behaviour and society in a variety of fields such as sociology, psychology, political science, economics or anthropology. The reason for having many specialised areas of research around human beings is that societal modelling is complex and can be studied from different approaches ((G. Gilbert \& Troitzsch, 2005)). Social systems are complex in three different ways (Rossiter, Noble, \& Bell, 2010):

- they are composed by many entities which interact between them with a high degree of interconnection which can introduce internal feedbacks,

- their structure and rules may vary over time so they have limited accuracy which in turn makes validation difficult,

- they have limited available historic data to work with.

So how could social researchers tackle their questions about change in social systems? As pointed by Kohler and van der Leeuw(Kohler \& Leeuw, 2007) the fieldwork could be a place to start but it is not enough to answer all questions. Therefore social scientists need to build models as possible explanations to contrast their theories and their data.

Computational modelling and analysis can handle systems with complex, dynamic, and interrelated parts, such as epidemics spread and extinction of an ethnic group, which occur within a context constrained by many socio-economic factors. It can also handle the emergence of social patterns from individual interactions. In that way, a part of computational modelling is to be capable of model a person as an agent and his social relationships as networks. In this chapter we want to show the nature of social simulation and why it is becoming so popular, we will also discuss modelling procedure and why simulation looks suitable for applications in social science and humanities.

\section{A brief history of social science simulation}

The study of real world with simulation technologies in the social sciences started in the earlies 1960s (Troitzsch, 1997) with the advances and developments on computer. In the beginning, the research on simulation focused mainly in discrete-event simulation and in System Dynamics which took advantage of the big calculus capacity of computers. System Dynamics approach uses big systems of differential equations to plot variables trajectories over time (Hanneman, 1988). Sterman (Sterman, 2000) describes it as "a powerful method to gain useful insight into situations of dynamics complexity and policy resistance". However, System Dynamics is restricted to the social analysis at macro-level and it could only allow models that could be translated into equations.

In the early stages, simulation focused more on the prediction of social systems more on their understanding (G. Gilbert \& Troitzsch, 2005). To respond to policy concerns, another approach of the same period to model social behaviour appeared, known as microsimulation (Orcutt, 1957). Microsimulation which aims modelling the evolution of population dynamics over time through specifying a random sampling process for each individual at every simulation time point. Although microsimulation has no pretensions to explanation but to predict as system dynamics, it is interesting that the unit of simulation is the individual with no attempt to model interactions between them. During many years, microsimulation was the only form of simulation which was widespread recognized by social scientists. Still today it is used in many countries for policy issues.

In the 1980s, advances came from mathematics and physics, specially those working in the artificial intelligence field. In these years, cellular automata (Von Neumann, 1966) start to be used to understand social interaction. Cellular automata are a mathematical kind of models that simulate dynamic systems which evolve in discreet steps. They consist of a grid where every square is known as cell. Each cell has concrete state in each moment of time and also a set of neighbours. In each 
step of time a transition function is applied homogeneously to each cell taking into account the cell state and also the neighbours states, so a new state is assigned to that cell.

In the 1990s a new technique from the artificial intelligence domain which allows autonomous objective-driven movements in grids is born: multi-agent based systems (Weiss, 1999). Artificial intelligence deals with the processes of life and how to better understand them by simulating them with computers. The field started with the beginning of computing, focusing in the modelling of individual cognition. Later, just until the computer capacity increased and the apparition of Internet, artificial intelligence researchers develop the distributed computing in form of autonomous independent entities able to interact, also called agents. From 1980s, artificial intelligence community also developed techniques of "machine learning" which are systems with the ability to learn from experience, adding the new information to their knowledge and procedural skills (Michalski, Carbonell, \& Mitchell, 1985).

Not until the half of 1990s game theory is born, a discipline that includes models more directly related to our current simulations. Game theory are a set of mathematical models that study of interactions and decisions of people in competing environments (Aumann, 1985). Also in later half of the 20th century, new advances in computing allow to combine cellular automata with game theory and apply them to social sciences. One of the most well known of that is the Life Game of Conway (Gardner, 1970) where with four simple rules a cellular automata is build to simulate the life of a complex organisms society which interact between them.

Despite being relatively new, the agent-based simulation community is growing fast. This is due mainly to its potential, in particular to the domains where location (as social networks, where nodes and connections are essential (Wasserman, 1994)) and distribution (not centralised or organised by a hierarchy although it is possible to set some layers of organisation) are very important, in front of other equation-based models, more suitable for central systems that can be understand more by physical laws than by information processes (Menéndez \& Collado, 2007).

\section{Why model?}

The concept of modelling is widely extended. It comes from the natural observation of the world and the curiosity or need to reproduce it. As Epstein (J. Epstein, 2008) says "Anyone who ventures a projection, or imagines how a social dynamic - an epidemic, war, or migration-would unfold is running some model". The challenge is to write it down, to turn it from implicit where assumptions or data are hidden to explicit. It does not matter if the model implies a mathematical formulation or any kind of graphical representation. Models are approximations to reality for an intended used (Pidd, 2010). Pidd proposes a graphical representation of a model as a box with inputs and outputs. The box will be black or grey depending on the purpose of the model. If one wished to perform controlled experimentation as in some areas of physical science, the box will be black since the model will be analysed through its outputs under defined inputs. On the contrary, if the box is grey that means we have some knowledge of the model's interior processes. That is the most suitable case when investigating case scenarios answering "what if" questions. The analyst part should be studied and it could display some unexpected emergent behaviour, a consequence of the internal dynamic interactions between the variables in the system.

In social sciences and humanities, the tradition to apply mathematical models is not very extended, with the exception of economy and sociology areas (Rubio, 2009). Common mathematical models in these fields are based on differential equations which are very useful to describe continuous systems but experience more difficulties in systems where the interest is on the interac- 
tions between discreet entities, as human being can be. Moreover, to model individuals as discreet autonomous entities looks more natural. Given the difficulties to apply differential equations, statistical techniques have commonly been used as a powerful analysis tool (Stewart, 1990). They are able to extract general patterns from a set of data which does not appear to have a regular behaviour. However, statistical analysis provide models that indicates tendencies in a sample of values of variables. Therefore the information we can generate is very limited, particularly in forecasting and hypothesis testing.

Indeed simulation is specially suitable when we want to conduct experiments with a model in order to understand the behaviour of the system under study (Shannon, 1976). Therefore, simulation is one of the more powerful methodological approach that a researcher can use to understand a complex system. Actually representation of reality through simulation models are often closer to reality processes than other mathematical models (Lozares Colina, 2004). Simulation not only includes the construction of a model to study the system dynamics of interest but also it can generate new knowledge that can have an impact on the model formulation itself. For instance new hypothesis might arise which can turn on model refinement. The ultimate objective is to get closer to the answer of the initial formulated questions about the real world. According to Shannon, simulation process should start with the definition of a problem, analysing the important entities which play a role and the relations between variables, followed by a model formulation. At this stage it is important to decide the number of variables to take into account, since a balance is needed between simplicity and complexity. The model should have as many variables as needed to answer the initial questions. However, it is possible to refine it in later states of simulation process.

\section{How to model}

It is not ventured to say that modelling is one of the keys to do research. A model has impact in all aspects of a simulation study. But which is the process of modelling? Law (Law, 2007) describes in the following way. When trying to simulate the real world we talk about systems of interest, which are a "collection of entities that act and interact together toward the accomplishment of some logical end". To study them, modellers start from a set of thoughts in the stake-holder's mind around a problem or theory of interest. This set of ideas refer to the structure of the problem: its objectives, the input and outputs of the system and its content (Robinson, 2008). In this process, some assumptions and simplifications are made. Robinson states that these assumptions help dealing with uncertainties or beliefs about the real world (the scope of the model), while simplifications help reducing the complexity of the model (its level of detail). According to Robinson, all this components form the conceptual model, which gives us an insight of the behaviour of the system. The process of building a model from a real or proposed system is called conceptual modelling. In Figure 1 , Heath et al. show how conceptual modelling is embedded in a simplified simulation development process (Heath, Hill, \& Ciarallo, 2009). As we can see, the previous steps of formalising a model is to formulate a problem and the objectives of the simulation study.

Despite the importance of the conceptual model in a simulation study, there is not agreement in the definition of what a conceptual model is. In (Onggo, 2010) it is suggested it might be due to the wide variety of conceptual model representations which have been proposed in the literature. What seems clear is that conceptual modelling is very close to the notion of abstraction, which is related to computer science and has originated many specification languages (Roussopoulos \& Karagiannis, 2009). To make this abstraction process effective an appropriate simplification of reality is needed (Pidd, 2003). That is, we need to set the boundaries of the real world portion we 


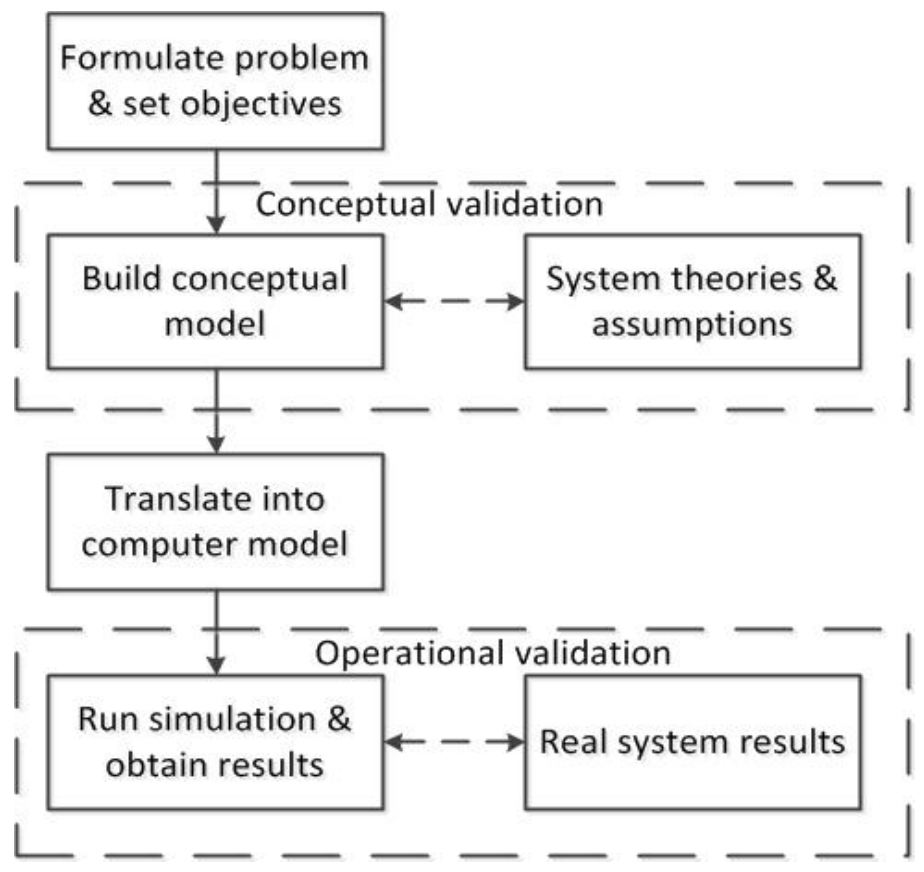

Figure 1. Conceptual modelling in a simplified simulation development process by (Heath, Hill, \& Ciarallo 2009)

want to model in an appropriate way that can give answer to the question we make. Despite this process of simplification, a model should be complex enough to answer the question raised (Banks, 1998). For example, a model that emulates a vehicle routing problem can answer question on how a company should distribute its products in a given network. However, this model can not answer questions on how this distribution will impact on the current traffic of the network. If we were interested on getting information on the traffic impact, we should enlarge our model to model the traffic flow to calculate how a given distribution of vehicles will affect it.

Thus, we need to find a balance between real world and the conceptualized system. If we directly consider the most complex model to do an study we will encounter several problems, being the most important its credibility. How could we be certain that the non necessary components in our model are not affecting the results? As Robinson states simple models have many advantages, such as they are faster, require less data, are more flexible and, more importantly, if we better understand them we can better interpret their results (Robinson, 2008). In fact, a good modelling design enhances the probability of simulation study success. Nevertheless, not in all research areas simplicity is seen as a positive value. For instance in the social sciences, Leeuw (Leeuw, 2004) states archaeologists can not presume a simple behaviour until there is some evidence of it. As Davies et al. stay one should be careful to simplify certain natural processes since it presumes certain assumptions about how they operate so one could miss some important facet to explain it (Davies, Roderick, \& Raftery, 2003). The tendency however is to build KISS (Keep it simple, stupid) models. Idea which stems from Occam's razor: things should be kept as simple as possible and made as little more complex as explanation purposes demand (Axelrod, 1997). Applied to social simulation, KISS ideally seeks simple and abstract models that are general enough to be explanatory 
for multiple specific cases. Also in social sciences and humanities there is a particular difficulty when doing conceptual modelling: sometimes data is not available or non-existent. Stakeholders need to proceed other way by filling out the abstract social process or mechanism sufficiently to create a working implementation, focusing more on the instantiation of the desired mechanism than in being faithfully to the observation of the real world process (Yang \& Gilbert, 2008).

One important property of the conceptual model is that it is not oriented to any software, so stakeholders free from implementation concerns. Thus being able to represent the behaviour of a phenomenon or problem which can be later solved in the preferred computational methodology. Separating the modelling and coding process allow modellers to focus on developing the more appropriate ("right") model to perform the study of interest (Robinson, 2008). Thus allowing all stakeholders to integrate in a simulation project (Roussopoulos \& Karagiannis, 2009). This condition makes possible to communicate the model between them, to discuss different points of views and to set common objectives. Therefore, a collaborative effort is needed since they might probably come from different domain knowledge and expertise (Chen et al., 2008). To do that, Nance states that stakeholders should pick up an standard representation to understand the concepts and ideas keeping in mind that a good communication process enriches the simulation model (Nance, 1994).

\section{Modelling with formal languages}

In social sciences and humanities, models are often expressed through natural language, which is inherently ambiguous. This is due to the nature of systems involved in their studies, which are often very complex in reasoning and suppositions. Moreover, each research discipline has its own vocabulary and approach which causes more confusion. To avoid misunderstandings, scientists should express the phenomena and ideas under study in the same rigorous manner (Leeuw, 2004). That is, they should formalise their models, meaning they should describe the social system under study with a non-ambiguous language. With a formal language of that kind they can non-ambiguously describe their models which allow them to understand, specify and analyse a system. As we said before, there is a clear advantage on doing so when teams are formed by experts from different areas of science. Formal models provide the way to make these interdisciplinary teams effectively work.

Between the natural language and a formal language, there are some alternative methods which can be used to describe social systems. For instance, Onggo points out at the use of diagrams for conceptual representation, which can show the information in two dimensions, being the activity cycle diagram, the process flow diagram and the event relationship map the most widely used (Onggo, 2010). Despite their usefulness, Onggo states it is not common that a single diagram could be used to represent completely a conceptual model.

In the area of social sciences we can also find the protocol Overview, Design concepts and Details (ODD), which goes beyond textual representation (Grimm et al., 2006). ODD is aimed for a description of individual-based models. It is meant to describe readable and completely the system of interest, through an structure for the description and guidelines for the contents, so all important information is captured. In (Polhill, Parker, Brown, \& Grimm, 2008) a more extensive description of ODD can be found along with an example of application to social simulation of landuse change. An example of ODD structe of a case study on agent-based simulation can be seen in Figure 2. The main limitation of ODD is that is expressed in natural language, thus being subject to ambiguity. However, it is easy to build a computational model from it and helps make the theoretical foundations of large models more visible. Despite its potential and having reach certain popularity, 


\section{CS1: Hunter-Gatherer persistence in arid margins. The case of N Gujarat (India).}

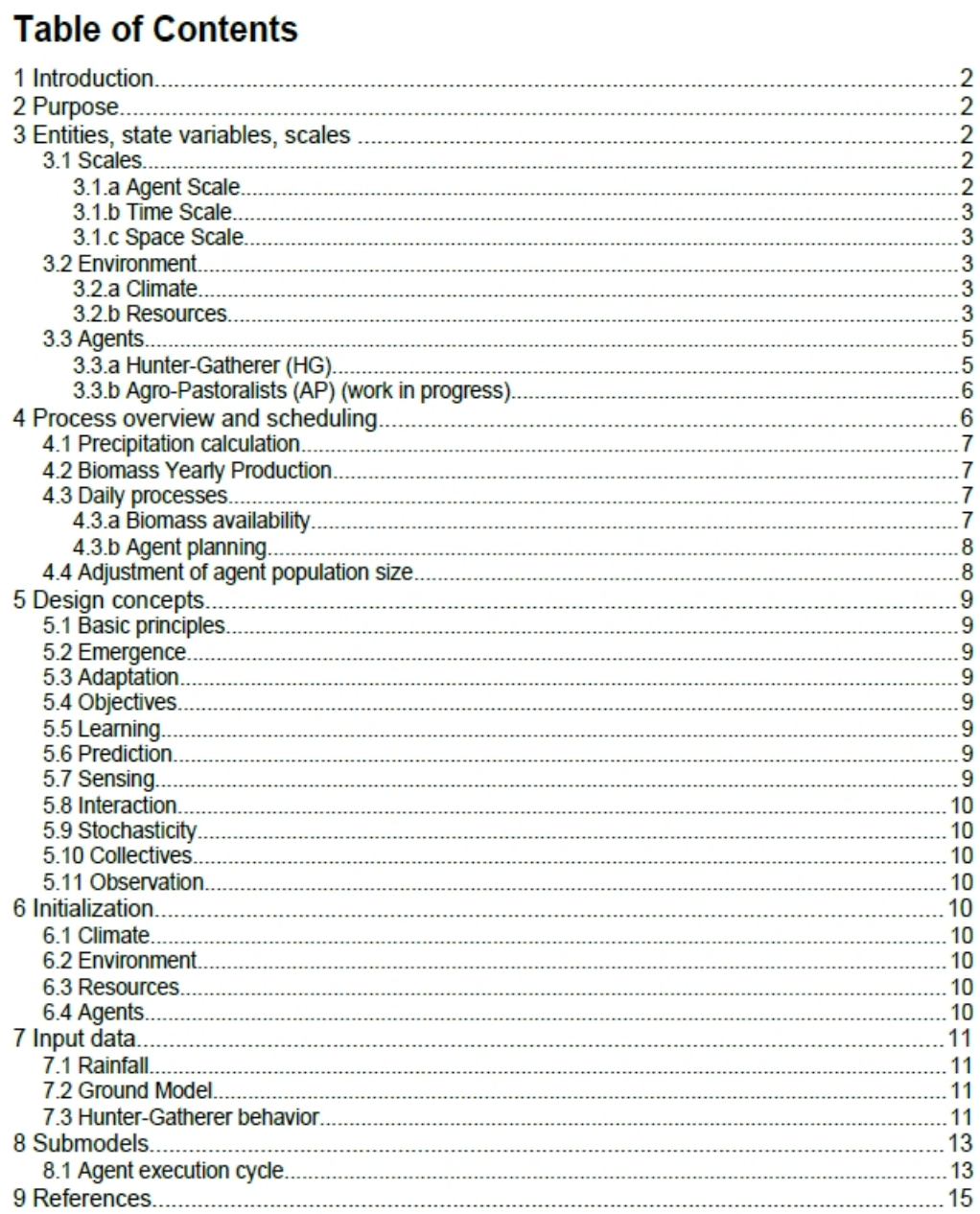

Figure 2. ODD structure of on agent-based simulation of hunter gatherers persistence in arid margins in Gujarat (India). This case study is part of the Simulpast Project (CSD2010-00034) funded by the CONSOLIDER-INGENIO2010 program of the Ministry of Science and Innovation - Spain. 
more work and refinement of ODD should be done (Grimm et al., 2010).

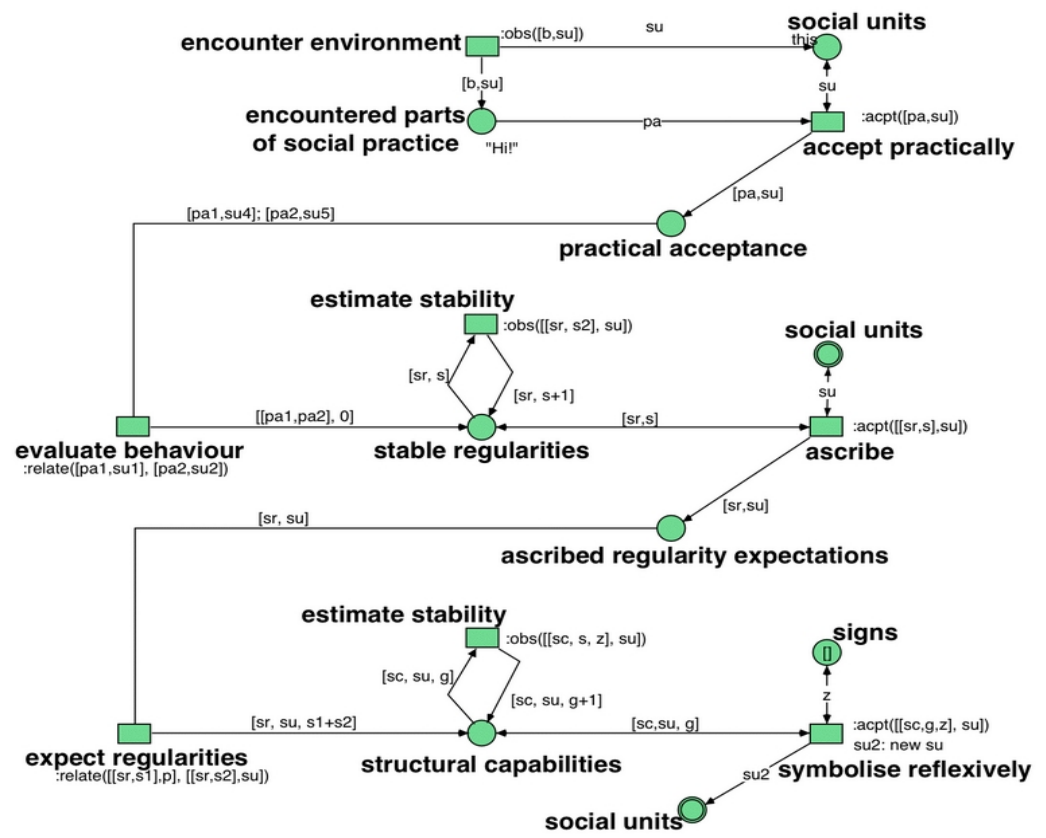

Figure 3. Petri Nets example of a model to simulate the Theory of Social Self-Organisation by (Köhler et al., 2007)

The ideal would be to use formal methods to simulate social processes as other formalisms are commonly used in other applications of simulation, such as Discrete Event System Specification (DEVS) or Petri Nets, both mathematical kind modelling languages. Formalisms provide a technique for specify the characteristics of a system and its dynamics besides helping to the validation process. On one hand, specification is very useful to implement models, specially when working in multidisciplinary research. On the other hand, validation allows automatic verification and error checking of simulation systems. However, we have to take into account that social simulation is quite new area of research and also that research mainly come from social fields with poor tradition of mathematical modelling.

An example of the application of Petri Nets to social systems can be found in the work of (Köhler et al., 2007) who used Petri Nets to model the Theory of Social Self-Organisation. Figure 3 shows their model.

Social scientist could also take advantage of other multifaceted representation to represent conceptual models. It consists of a set of diagrams to represent different components in a model. One of the most used multifaceted representations is Unified Modeling Language (UML) (Fowler $\&$ Scott, 2000). As other simulation formalisms, this type of solution allow to verify the consistency of conceptual model components (Onggo, 2010). In (Bersini, 2012) Bersini advocates for the use of UML in social simulation, specially for modelling agent-based models, a type of social models that will be later discuss in. In his words "we can only regret the minor diffusion of UML among researchers producing agent-based models and hope that this paper will improve the situation in the years to come ". Richiardi et al. propose to use at least part of UML in multiagent systems, 


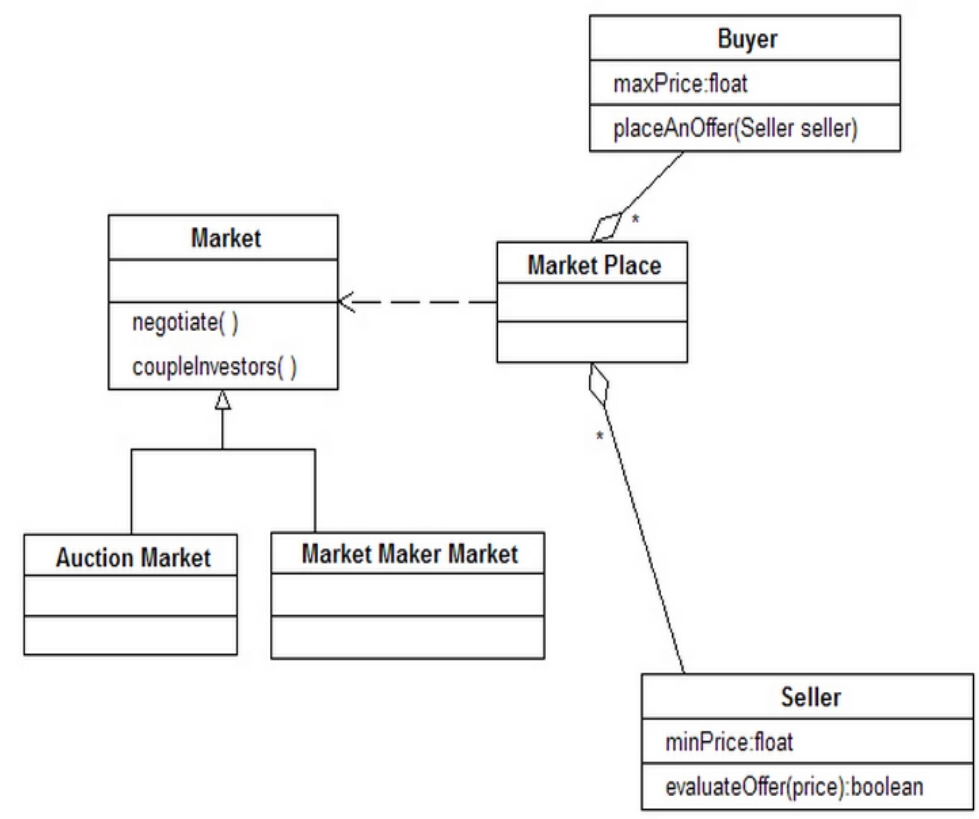

Figure 4. UML class diagram example of a market-seller system by (Richiardi, Leombruni, Saam, \& Sonnessa, 2006)

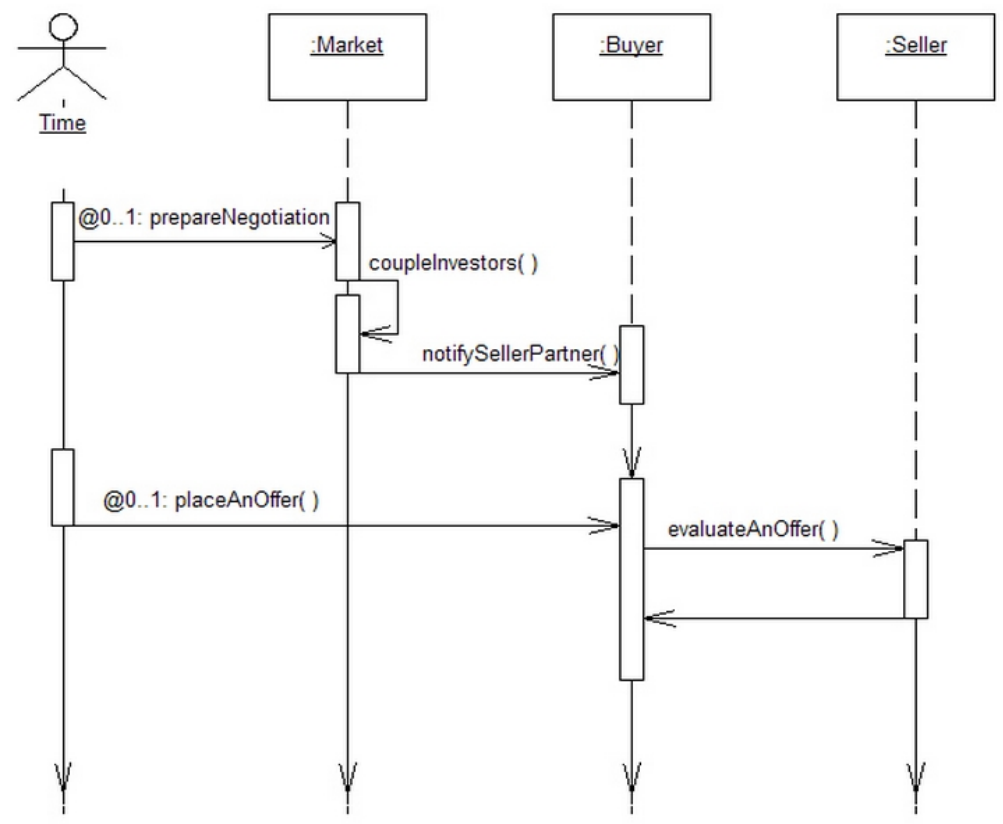

Figure 5. UML class diagram example of a market-seller system by (Richiardi, Leombruni, Saam, \& Sonnessa, 2006) 
specifically the static representation (Class Diagram) and the dynamic view (Sequence Diagram) (Richiardi, Leombruni, Saam, \& Sonnessa, 2006). An example of Richardi et al. of both types of diagrams can be seen in Figure 4 and Figure 5.

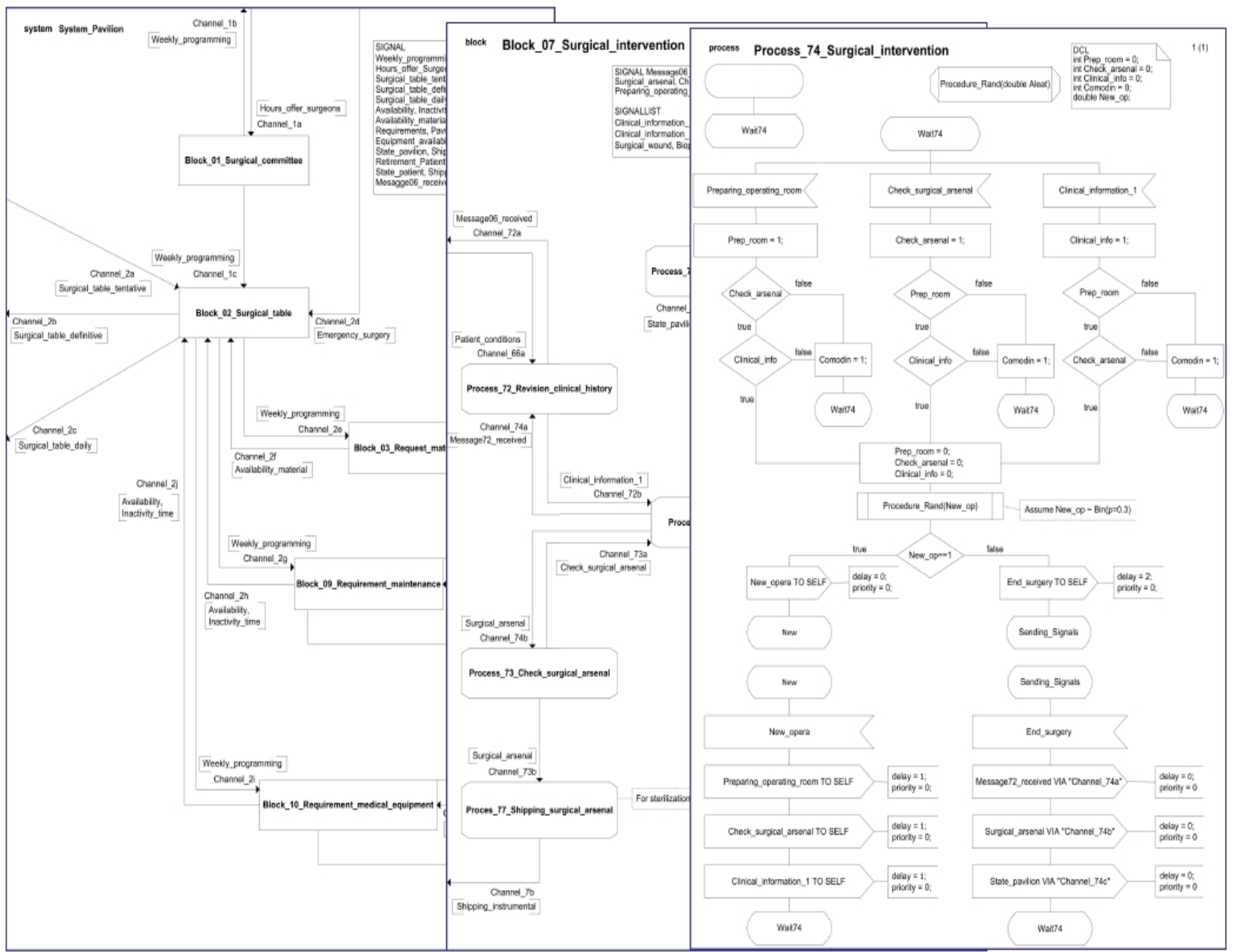

Figure 6. SDL example of an anesthesia unit and surgical pavilions on a hospital by

Another type of multifaceted representation named Specification and Description Language (SDL) has been used to describe social systems. Some examples of the use and application of SDL include the modelling of a simple reflexive intelligent agent (Fonseca, 2008), some industrial planning and management applications (Fonseca, Casanovas, Monero, \& Guasch, 2011) and modelling an anaesthesia unit of a Chilean hospital (Leiva Olmos, Fonseca, \& Ocaña, 2011). An example of SDL of the later work can be seen in Figure 6. The advantage of using a formalism like SDL or UML is that they are meant for distributed environment, thus being capable of reproducing largescale simulations. 


\section{Agent-based modelling in social sciences}

Agent-based models come from the area of Artificial Intelligence (AI), which tries to artificially create systems that think and act as human beings (Russell \& Norvig, 2010). In those terms, the unit of study is the agent. There is no standard definition of agent, although a commonly accepted one is from Huhns and Singh "a self-contained program that can control its actions, based on its perceptions of the environment" (Huhns \& Singh, 1997). Despite the disagreements of the AI community to find a definition for an agent, most authors consider agents should satisfied the following properties:

- Autonomy, understand as the capability to operate without the direct control of humans or other agents

- Interactive, as the social capacity to interact with their environment and/or with other agents besides perceiving their closest local environment

- Subjective perceptive, with limited capacity or reasoning

- Reactive, in the sense of perceiving their environment and acting in consequence, and proactive, capable of taking the initiative with a behaviour based on objectives

- Having the potential to add characteristics as adaptation, learning, complex planification and language

Therefore an agent will take decisions based on its perceptions in its own environment where it exists and its objectives. According to the method through which the agent takes its decision, we can classify agents in four categories (Russell \& Norvig, 2010):

- Simple reflex agents, which operate choosing an action from the perception of their environment. This type of agent has no memory and its behaviour is specified with if-then logical rules. Therefore, it is not really intelligent and will not be able to react to unexpected situations correctly.

- Model-based reflex agents. They operate also with individual logical rules but additionally have a model of the environment, whose rules take into account to take their decisions.

- Goal-based agents. This type of agents are designed with objectives, not only with logical rules. Objectives can be in the long run or in the short run. Therefore, these incorporate a planification so agent can achieve their goals.

- Utility-based agents, they not only take into account their objectives but also can distinguish between the best way to achieve them. To do that they incorporate an utility function which serves to measure the best strategy.

- Learning agents, which are able to initially operate in unknown environments and to become more competent than its initial knowledge alone might allow.

One of the first questions modellers need to answer when building agent-based models is to model at the individual level or at the aggregate. The election should depend on the purpose of 
the model. For example, if we want to understand the dynamics of a crowd we might be interested on understanding the factors that drive the behaviour of every individual from a psychological perspective. In that case, an agent-based model at the individual level looks more promising, such Madhavan et al. propose (Madhavan, Papelis, Kady, \& Moya, 2009). However, if the object of interest is to deep on the density evolution of a crowd either a continuous-field models or aggregates of individuals could be possible (Goodchild, 2005). The size of the crowd could change our decision, since the more variables intervene in a model the more difficulties researchers could encounter to understand them. Actually setting constraints is essential for agent-based models, since we cannot produce an unlimited number of models to generate an unlimited number of scenarios for social dynamics (Moss, 2001).

Simple observation of real world leads us to the idea of patterns. There is a numerous number of patterns in reality. They are usually the result of the interactions of smaller pieces that somehow combine in not so expected ways to create a large-scale pattern (Wilensky, 2002). These patterns or phenomena emerge arise out of interaction of numerous individuals (agents) at a micro-level. An example of emergent behaviour could be a flock of birds winging acting complete synchronized while there is no leader to follow. Agents might be a powerful tool to reproduce human behaviour in environment shared with multiple agents. Simulation of agent-based models also called agent-based simulation is a technique which allow us to integrate complex decision making of human being in an interactive context with other agents, with other variables that might be interesting for our model, such as geospatial factors. Agent-based simulation can can be used to detect patterns of behaviour under the hypothesis that those can emerge from the addition of individual decisions in a social model. Moreover, this property of emergence is specially interesting in situations where the modeller suspects or detects that dependent and independent variables alternate their role intermittently, which is very common in social sciences (Menéndez \& Collado, 2007). Menendez and Collado also state that agent-based simulation helps on treating the problem of establishing causality directions between variables, which they say is very useful in social sciences since independent and the dependent variables can alter their role intermittently. For instance, they point out at the example of religiosity, where one could expect that religious change may vary in function of personal values but also the contrary could be correct.

Which is the goal of studying population dynamics with agent-based simulation? Based on the modeller level of understanding of the system under study, Heath et al. (Heath et al., 2009) distinguish three types of purposes for simulation. When the level of understanding is high the simulation model can be used as a predictor, producing precise forecast of future behaviour under well defined conditions. When that level of understanding is in a medium stage, the simulator turns to a mediator providing insight into the system without offering a complete representation of its behaviour. Mediator simulation models can be used to test theories and their results can be used to improve the simulation. Finally when low information about the model is available the use of simulation is as a generator, generating hypotheses and theories about the system behaviour. Concretely in social sciences, Menendez and Collado (Menéndez \& Collado, 2007) state there are two goals of simulation. First one is to verify if a social model is coherent and adjusts adequately. In fact, when data is non existent the parameter space is explored to find the optimal adjust for unknown variables. Once the simulation model behaves as expected new hypothesis can be introduce, observing if the model reflects the real behaviour. This is specially useful when we have qualitative data and they do not know how to quantify it. With trial and error it is possible to modify parameters until observing the behaviour of interest. Through those parameters we can find out their relationships and mutual 
influence. Second one is to virtually defy big limitations on experimenting in these areas, since some hypothesis can not be tested otherwise by recreating empirical situations. Therefore simulation can improve explanatory or even predictable capacities of models. However, if the knowledge in models is poor so the results of simulation will be, resulting simulation not useful at all.

Moss (Moss, 2001) states that agent-based simulation can be useful in social sciences to

- to restate and assess existing theories, which are often sociological and anthropological

- take advantage of sociological theories and concepts to inform simulation models

- as a formalise description of a system

- to analyse different scenarios

- to help in policy analysis and formation

Beyond these interests, Moss point out at the foundational purpose agent based social simulation which is to develop a general social theory. Axtell et al. made an attempt to find out how general individual models might be by aligning some of them (Axtell, Axelrod, Epstein, \& Cohen, 1996) but Moss says it is far from being general. Simulation can provide insights and hypotheses on population dynamics but theories on social behaviour might be more relevant in the field (Bankes, 2002). That is the reason why Moss suggests there is no universally accepted theory of social process. Moreover, it explains why there has been very little use of agent-based models to recommend public policy.

A second reason for the importance of agent-based simulation in the field of social sciences and humanities is its naturalness as representational formalism in this field (Bankes, 2002). It provides a way to express the vast amount of data and knowledge about social agents characteristics, including their behaviour, motivations, and relationships with other individuals or institutions. However, there are some areas of agent-based simulation that needs further attention such as the calibration of models to data and which should be the methodology to use this kind of models to answer specific questions or to solve problems.

Finally, agent-based approach to simulation is flexible since agent can be defined within any given system environment, and move on it freely (Castle \& Crooks, 2006). In that way it is possible to define geospatial reference of agents through variables and parameters of the simulation. Moreover, agent interactions can be governed by space and networks, or a combination of the two, which will be more complicated to explain by mathematical formulation (Axtell, 2000).

Despite those advantages, agent-based simulation has also some limitations. In sociology, some researchers find difficulties on applying agent-based simulation models due to the lack of knowledge in some social phenomena. This lack might be not only due to empirical evidence but also to limitations on sociological theory. An example of these type of problems can be found in (Menéndez \& Collado, 2007), where Menendez and Collado try to study religious evolution in Spanish society by the end of last century. As a conclusion of their study they point out at the need of finding more formal and documented models which should be able to explain systematically social processes. Another disadvantage of this approach is the lack of full access to data relating to the phenomenon of interest, because the target of interest is not easy to access or simply data is non-existent. There is also a limit on the size of parameter space that can be checked for robustness when conducting agent-based simulation. If we increase the number variables we not only increase 
computational needs but also we compromise the credibility of the model, which is very difficult to validate against real data (Castle \& Crooks, 2006).

\section{Some applications in social sciences}

Among numerous applications of agent-based simulation to the social science, Schelling (Schelling, 1971) is credited with developing the first social agent-based model. In his work, he reproduced population dynamics in terms of segregation patterns. His work show this patterns can emerge from migratory movements of two different culture types of households, which were quite tolerant. Later some other social models using the agent-based approached arose, such as Sugarscape (J. Epstein \& Axtell, 1996).Despite the simple behaviour of agents, Sugarscape results illustrate a variety of features of societies, including emergence of social networks, trade and markets, and cultural differentiation and evolution. Another icon model of the agent-based modelling community is the Artificial Anasazi model (Dean et al., 2000)(G. Epstein \& Gang, 2006) which describes the population dynamics in the Long House Valley in Arizona between 800 and 1350. The model help to prove that simulation could reproduce settlements archaeological records on the occupation of the Anasazi in Long House Valley with simple household rules on choosing locations for farms. Moreover, the model showed that the abandonment of the valley around 1300 cannot be explained only by environmental variations.

In this section we do not pretend to revise the full range of agent-based simulation application but also point out some examples of interest. We can find examples in very different areas. Archaeologists and anthropologists are also using agent-based simulations of ancient civilizations to help explain their growth and decline, based on archaeological data. An example of that is Villatoro and Sabaté-Mir (Villatoro \& Sabater-Mir, 2008) who studied the Yamana indigenous of Tierra del Fuego (Patagonia) to deep in the factors which lead this hunter-gatherer society to extinction. In their study they provide that despite living in very hostile geographical conditions Yamana had a strong organisation and a set of norms that made possible a high interaction between different groups. For that, they used an agent-based simulation where agent had a set of simple logical rules.

In economy, we can find numerous applications of agent-based simulation. An early example on evolutionary trade network formation among strategically interacting buyers, sellers, and dealers. networks is from Epstein (J. Epstein \& Axtell, 1996), Another example to reproduce dynamics in queues, such those of costumers in check-in desks, banks or airports can be found in (G. Gilbert $\&$ Troitzsch, 2005). Also economical factors are considered in the agent-based model of Balbi and Giupponi of adaptation to climate change (Balbi \& Giupponi, 2010). Tesfatsion give some more example of applications of agent-based modelling and simulation to economic systems (Tesfatsion, 2002) (Tesfatsion, 2006).

Sociologist are also working on agent-based modelling. Cognitive science is starting to extend the idea of artificial agents to social settings (Bedau, 2003). In that sense, Gratch and Marsella use agent-based simulation to study the influence of emotion and cognition on social behaviour (Gratch \& Marsella, 2001). Menendez and Collado (Menéndez \& Collado, 2007) studied religious change in Spain by the end of last century and how it which might be tied to values change.

If we add more intelligence to agents, such as orientating them rationally based on belief, desires and intentions aligned with psychological theory, we can find application in the simulation of traffic where drivers take their decisions based on their perceptions of traffic flow and characteristics (El Hadouaj, Drogoul, \& Espié, 2001). Or simulation of emergency situations, such as fire emergency in an airport where agents need to decide their way to escape (Burmeister, Haddadi, \& 
Mattilys, 1997). However, as Menendez and Collado (Menéndez \& Collado, 2007) states sometimes it is not possible to precisely define desires and intentions which move human beings in the society to simulate them.

To conclude, we can say that although there is a lot of work done in agent-based simulation in social sciences there is much more to do. Specially the use of agent-based models for experimenting with geographical phenomena needs further work (Castle \& Crooks, 2006). However, agent-based simulation has the potential to achieve remarkable goals in the areas of social sciences and humanities.

\section{Tools for modelling in social simulation}

There is a lot of interest in developing agent-based modelling as a general technique to be applied to the study of societies. A numerous number of platforms exists to provide the means to study social phenomena. In this section, we will briefly describe some of them and compare them in terms of software capacity, architecture and the type of applications they have been tested with. We have chosen the software platforms we currently believe to be of particular relevance to scientific modelling and simulation of societies. We do not intend to fully review them but just to revise their most important characteristics to help the reader picture the world of agent-based simulation tools. A more completed list on software platforms for agent-based modelling and simulation can be found in (Nikolai \& Madey, 2011) and (List of ABM tools, n.d.).

Agent-based systems are very complex applications to program, implement and optimise, specially when the size of the population to simulate is large. Actually, we can find two different situations when modelling and simulating social behaviour. On one hand, there is a computer scientist or someone with advanced skills in mathematical programming which faces the challenge to realize some research in a social domain. Unless he/she has the adequate knowledge in the sociological model, he/she will experience difficulties to build a valid model and later explain and communicate it to the social community. On the other hand, we could find a social scientist who wants to take advantage of simulation techniques to experiment with his/her theories and knowledge. Unless he/she has the programming experience to develop and implement his/her ideas, he/she will need to find someone to do that for him/her. The ideal case, therefore, would be the situation where the social scientist could autonomously use a tool to define his/her models and afterwards run them. Similarly when social scientists perform a multivariate analysis through a statistical tool without the need of programming or knowing in deep the mathematical algorithms involved, they should be able to test their hypothesis or theories. Thus, the need to give a boost in developing tools to help research community advance in the social simulation field.

Nowadays we can find numerous tools to experiment in social behaviour and dynamics. Moreover, as computer technology has advanced, the scale and sophistication of the software available for users has increased. Software toolkits might be difficult to handle, specially when they use object oriented languages. In that sense, Nicolai and Madey (Nikolai \& Madey, 2009) point out that the use of object oriented languages is very extended: $42 \%$ use Java as their primary programming language, $17 \%$ uses $\mathrm{C}++, 11 \%$ uses, $8 \%$ uses a variant of Logo and the rest use a platform specific language which was designed to facilitate the modelling and simulation design. In fact, there is little consensus about the best general purpose programming language to use on simulation social behaviour (N. Gilbert \& Bankes, 2002). Given the number of different programming languages that can be used, agent based modelling packages tend to be hard to understand for users who may have little or no programming experience, as social scientists generally are the case. 
Apart from that, each tool has its own non-intuitive terminology so users should learn how to draw or write their models in each particular platform (Allan, 2010). This is due to the multidisciplinary nature of social agent based modelling field, so easily there might be a conflict in the use of terms. Moreover, Nicolai and Madey (Nikolai \& Madey, 2009) state that there is no consistency in the use of terminology in some toolkits. For example, they point at the term "multi-agent system" which properly refers to a small system with heterogeneous agents that have artificial intelligence capabilities and it is in some cases used to refer to a large system of homogeneous agents (an agentbased system). These slightly differences on the concepts employment can mislead the user or create difficulties in work teams. Depending on the user's background, the characteristics of the platform should be different. For instance, social scientist might be more concerned about how easily is the interaction with the interface to manage simulations and the degree of programming skills required while computer scientists may consider if the tool is open source and its capability to be modified or extended for their own purposes. But no matter which type of user should the tool be meant for, they should have a good documentation. However, basic documentation is incomplete in general although there are some exceptions with very detailed information (Allan, 2010). It mainly depends on how extended is the community using the tool and the community that supports its development.

Beyond that, there is no standard on how to specify agent based models not only in the social science and humanities community but also in the computer science, and specifically in artificial science fields. That fact makes difficult to address the issue on how defining the agents' characteristics, the interactions between them and with the environment. As a consequence, the platforms we can find nowadays address that issue in their proper way, according to the type of applications they are meant for, their characteristics, and what the tool designers think can be more convenient for their type of users. Consequently, it is not surprising to see that several tools have their own language which is used specifically for that toolkit, as we mentioned before. Some of them, probably concerned about becoming simpler to learn and use, have support for visual programming (Nikolai \& Madey, 2009).

There is another element that should be considered when modelling social dynamics. Sometimes models depend on the location of the phenomena being modelled, such that if one or more of those locations change the model results will also change (Wegener, 2000). Geographical location of agents is specially interesting for areas such as archaeology, history or ecology. Geographical Information Systems (GIS) are commonly used for representing data of geospatial nature. A GIS consist of a set of tools which allow users to interact and understand spacial information. GIS are meant for visualizing, processing and analysing spatial data presented as digital maps. In that sense, Wheatley and Gillings (Wheatley \& Gillings, 2000) called it an spatial toolbox. A GIS can not only deal with data at an geographical scale but also with data not properly geographical such as culture, political ideology or religion since it this kind of information can be attached to an spatial reference (Rubio, 2009). A good revision of GIS techniques and capabilities can be found in (Castle \& Crooks, 2006).

In the following subsections we will briefly describe the characteristics of four different tools which are most commonly used when simulating societies from the social scientist perspective. Those are: Swarm, Mason, Netlogo and Repast. Although they were originally designed as general purpose tools, as an educational tool and as specific tool for social scientific use respectively, we can nowadays find applications in social simulation in all of them. These differences on the primary domain of application might not only affect the user interaction with the toolkit but also the fact some of them have become more popular among some specific areas of social studies and human- 
ities. There is another aspect to consider in terms of characteristics of the software. In terms of use, some of them are open source while some others have a private license. Moreover, some tools support distributed environments and therefore can model large-scale populations. In this report, we decided to not include tools with education purpose, although there is a lot of interest on it (Serenko \& B., 2002). Instead of that, we focus on platforms meant to develop and experiment simulation of social systems.

\section{Swarm}

Swarm is one of the oldest agent-based modelling toolkits developed in Santa Fe Institute (Minar, Burkhart, Langton, \& Askenazi, 1996). It is intended for general purpose applications, specially those related to artificial intelligence, to develop multi-agent models to simulate complex adaptive systems. Right now, Swarm development and management is under control of Swarm Development Group (Swarm Development Group, n.d.). In Swarm users can not only implement their models but also observe and conduct experiments on the model in the virtual laboratory it provides. The design of models follows a schema of a hierarchy of swarms. A swarm is a group of agents and a schedule of actions that the agents execute. It is possible to design hierarchies of swarms whereby an agent can be composed of swarms of other agents in nested structures. When this happens, the agent behaviour at the higher level is defined by the emergent phenomena of the agents inside its swarm (Minar et al., 1996). Swarm separates the model from its observation. This property enables the model itself to remain unchanged if the observation code is modified. According to Allan (Allan, 2010) the design philosophy appears aimed for may different models profiting Swarm's modelling concepts, not including specific tools to any particular domain.

Swarm simulations can be written mainly in Objective-C and some in Java, both object oriented languages. Therefore a knowledge on object oriented programming is desirable. Swarm has a free source code form under the license GNU General Public License (GPL), which implies to make the source code for their entire model available to anyone who obtains a legitimate copy of the model's binary code. It runs in Windows, Linux, Mac and OS X operating systems. Swarm has no support for Geographical Information Systems (GIS) although there is an extension of Swarm simulation libraries named Kenge that provides functionalities to create cellular automata similar to raster GIS data layers, a surface upon which agents can act (Box, 2002). To date, it appears there is not any parallel implementation of Swarm.

Swarm has been applied to a variety of domains. We can find works in organisation management, for instance the work of Lin and Pai (Lin \& Pai, 2000) to simulate changing business processes to adapt to new business environments. Also there are several contributions to economics (Luna \& Stefansson, 2000) and supply chains (Strader, Lin, \& Shaw, 1998). In more technological areas, we can find applications in mobile technology (Lingnau \& Drobnik, 1999) and in social networks of open source software development (Madey, Freeh, \& Tynan, 2002). Terna (Terna, 1998) shows how Swarm could be used in social science research and tries to approach Swarm terminology and work environment to social science community. To do that, he presents an application of Swarm to a negotiation and exchange system of consumers and vendors. Also Axelrod (Axelrod, 1997) points out at how classical models, such as Game of Life or Prisoner's Dilemma, could be replicated with Swarm.

Traditionally, Swarm has been the most powerful and flexible simulation platform since it allows to implement very intricate and complicated social mechanisms (Allan, 2010). However, since the modeller needs to have some experience in Objective-C and possible Java, Swarm has 
a steep learning curve. That is the reason why despite the efforts on disseminating Swarm, it has remained technically challenging for most social scientist to use. Consequently, it has not generate a broad-based community of practitioners of this methodology in social science. However, given its history, Swarm definitely contributed to make agent based modelling more visible to a large number of scientists (M. Janssen, Alessa, Barton, Bergin, \& Lee, 2008).

\section{Netlogo}

Netlogo is an agent-based programming language and modelling environment for simulating complex phenomena. Netlogo derives from StarLogo (Resnick, 1994) and StarLogoT (StarLogoT, n.d.), an environment for experiment complex dynamics in parallel environments in Macintosh operating system. Netlogo was designed to provide a basic laboratory for teaching complexity concepts. To help doing that, it provides a graphical user interface to create models that control graphic agents that reside in a world in form of a grid of cells, which can be monitored. Since its ultimate goal is to be helpful in teaching agent-based simulation, the environment and the language in Netlogo is meant to be simple enough "to have a low threshold for beginners" (Tisue \& Wilensky, 2004). Therefore, Netlogo includes a large number of example simulations to help beginning and experienced users alike. In (Tisue \& Wilensky, 2004) the reader can find some useful information about Netlogo, including the history of its origins, a tour of its interface, an introduction to the Netlogo language, and the acceptance of Netlogo in the research community.

Netlogo uses a modified version of the Logo programming language (Harvey, 1997). This is a different approach from other toolkits such as Swarm and Repast which make simulation facilities available to programs written in a general-purpose language such as Java. Despite being free, Netlogo is not open source. Netlogo is written in Java so can be run on all major platforms, requiring Java version 1.4 to run the current Netlogo version 2.0. In principle, it can run in any operating system except for Windows 95 and MacOS 8 which were supported by previous Netlogo 1.3. According to Tisue and Wilensky (Tisue \& Wilensky, 2004), the majority of users find Netlogo fast enough for most purposes, specially when running simple code and large numbers of agents.

Although the Netlogo engine has no fixed limits on size, it is single-threaded, single processor based thus being problematic to run large scale models. To fix that, there is an extension of Netlogo called BehaviorSpace which allows the user to run will the simulation in parallel, one per core in a multiple processor cores desktop computer or in cluster of processors. BehaviourSpace was specially design to explore the parameter space of a model, exploring possible behaviours to determine which combinations of settings cause the behaviours of interest. BehaviourSpace is also free and open source.

There are many applications of agent-based social simulation in Netlogo. In (Damaceanu, 2008) an agent-based computational model is built to simulate the distribution of wealth in social classes, taking into account economies based on renewable and non-renewable resources. They conclude that global economy must focus on using renewable resources because this approach may increase the global wealth. Another interesting simulation with Netlogo is the work of Zhao and Li (Zhao \& Li, 2008). They conducted a study on reputation evaluation mechanisms using Netlogo. Albiero et al. (Albiero, Fitzek, \& Katz, 2007) used Netlogo to test a power saving technique for mobile devices in a cooperative framework for the wireless domain. In (Koper, 2005) a learning network is modelled to study how social interactions might affect acquiring new learning competences. In Millington et al. (Millington, Romero-Calcerrada, Wainwright, \& Perry, 2008) they used Netlogo to run an agent-based model of agricultural land-use decision-making to evaluate potential 
changes in wildfire risk for a Mediterranean landscape. Barcelo et al. (Barcelo et al., 2010) used Netlogo to simulate the emergence of ethnicity and cultural differentiation in prehistoric huntergatherer groups in Patagonia (Argentina). Also Netlogo can be used to replicate models, as Janssen (M. A. Janssen, 2009) uses it to replicate the Artificial Anasazi model.

As we can see, Netlogo is probably the simulation platform most widely used in Social Sciences and Humanities. The main reason is the smooth learning curve of the application, specially if it is compared to other software packages. A social scientist without any skill in programming can easily start developing models with Netlogo following a short course or a tutorial, and it is a huge advantage over platforms that require expert programming skills. Unfortunately, this fact is at the same time a disadvantage. Netlogo forces the user to create a model following the concepts and constraints defined by the program itself, and for this reason the researcher will run in trouble in case of creating a model that differs from the Netlogo approach. Moreover the code of this software is closed, so the possibilities of adapting the platform to other uses are weak.

In summary, Netlogo is a very popular tool in natural and social sciences community. Perhaps its success comes from its short learning curve and the extensive documentation and tutorials. Actually, Netlogo is known as being by far the most professional platform in its appearance and documentation (Allan, 2010). It is the perfect platform for prototyping the first versions of a model and exploring toy models, and an excellent tool to improve the understanding of social scientists regarding the process of modelling. However, it is not meant for large simulations with complex behaviour of agents and lots of interactions. For that, other alternatives should be explored.

Repast

The Recursive Porous Agent Simulation Toolkit (Repast) is a free open source toolkit that was developed by a collaboration between the University of Chicago and the Argonne National Laboratory, and is under constant development and extension (Collier, 2001). Repast is a set of Java libraries that allows to build simulation environments, create agents in social networks, collect data automatically from simulation and build user interfaces easily. Despite being designed for modelling social behaviour it is not limited to social simulation (North, Collier, \& Vos, 2006). It has a wide variety of applications that range from social systems, to evolutionary systems, to market modelling, to industrial analysis.

According to Allan (Allan, 2010), Repast has many similarities with Swarm, both in philosophy and appearance. Similarly it provides a library of code for designing, running, visualizing and collecting data from simulations. Those similarities are due to the fact that Repast was initially a Java re-coding of Swarm. However, Repast does not actually implement swarms. Since Repast was aimed to support social science domain, it includes specific tools for that field. Moreover, it was developed with the goal of being easy for inexperienced users. That could explain the development of different version of Repast: Repast-J in Java, Repast.Net in Microsoft .NET and Repast-Py in Python. However, currently these variants of Repast are no longer being developed, they have been replaced by Repast Symphony which provides all the core functionality of Repast-J or Repast.Net, although limited to implementation in Java. This last version improves specially the Graphical User Interface (GUI), provides hierarchical and organisation support through contexts and designs a special space for defining agents' relationships (called projections) (North \& Macal, 2005).

The Repast user community is large and active. Repast is available in both Java and Microsoft .NET forms. It is released under the Berkeley Software Distribution (BSD) license and therefore it is freely available for download with source code. In terms of architecture and computer 
capabilities, Repast Symphony has a concurrent and multi-threaded discrete event scheduler, it has available various numerical libraries such as random number generators and has distributed computing support using the Terracotta Enterprise Suite for Java. Point and click modelling in 2D and 3D is supported. In terms of documentation, although Repast provides some demonstration simulation models such as SugarScape, Swarm's Heatbugs and MouseTrap models, there are very few other simulation models generally available on the internet. However, a mailing list of Repast can provide general support and discussion.

Tobias and Hofmann (Tobias \& Hofmann, 2004) evaluated free Java-libraries for socialscientific agent based simulation and found Repast to be the clear winner. For that evaluation they focused in general aspects of the toolkit such as license, documentation, support, user base and future viability, modelling and experimentation aspects such as support for modelling, simulation control, experimentation or installation and modelling options such as inter-agent communication, networks and spatial arrangements. Also Allan (Allan, 2010) points at Repast as the being the agent-based modelling and simulation package with the greatest functionality.

Repast has many users involved in a variety of social domains. For example, we find applications in species explorations of landscape (Vidgen \& Padget, 2009), reputation systems (Schlosser, Voss, \& Brückner, 2005) (Wierzbicki \& Nielek, 2011), dynamics of insurgencies (Bennett, 2008), social influence and decision-making (Altaweel, Alessa, \& Kliskey, 2010) or evolutionary simulation (Edmonds, 2006). For other Repast application areas, such as evolution and ecosystems, artificial societies, and artificial biological systems see (North \& Macal, 2005).

\section{Mason}

Mason (Luke, Cioffi-Revilla, Panait, Sullivan, \& Balan, 2005) is the newest entrant into the field of agent-based simulation toolkits from our list of toolkits for social simulation. It was developed by a joint effort of George Mason University's Computer Science Department and the George Mason University Center for Social Complexity. The limitations of Repast with computationally demanding models with many agents executed over many iterations inspired Mason design as a smaller and faster alternative. Therefore, Mason is being developed as a new platform with emphasis on efficient execution of the code, which is programmed in Java language. It contains a model library and a suite of visualization tools in $2 \mathrm{D}$ and $3 \mathrm{D}$, both running independently. As one of the newest software tools, it has migration options from others which is interesting for developers. The system is open source and free (Allan, 2010).

There are many applications of Mason in social science. An example of that is the work on Dunham (Dunham, 2005) on epidemiological simulation. Cioffi-Revilla (Cioffi-Revilla, 2010) used Mason to study the emergency and evolution of polities in Inner Asia. Cioffi-Revilla, along with Bigbee and Luke, also showed how the Sugarspace model could be replicated with Mason in (Bigbee, Cioffi-Revilla, \& Luke, 2007). Luke and Ziparo (Luke \& Ziparo, 2010) used Mason to simulate virtual learning of automata. Other areas of application of Mason include climate change (Hailegiorgis et al., 2010), conflict (W. Kennedy et al., 2010)(Rouleau et al., 2009) or nomad societies (Cioffi-Revilla, Rogers, \& Latek, 2010). For a complete list of Mason applications see their website (http: / / cs.gmu.edu/ eclab/projects/mason/).

Allan (Allan, 2010) points out at the wide range of multi-agent simulations that can be designed with Mason ranging from swarm robotics to machine learning to social complexity environments. For more information about the Mason system and its basic architectural design see (Luke et al., 2005). 


\section{Discussion}

We have revised four widespread toolkits for agent-based simulations, including their needs, characteristics and some of their shortages. We specifically focused on applications to social sciences and humanities and pointed out at some special needs. In summary, social scientists experience some specific difficulties when managing agent-based platforms:

- On managing the interaction with the tool, including the need for a good detailed documentation and usability.

- On designing agent-based models they generally have non-existing or basic programming skills

- On defining the kind of features specific to social sciences and humanities (learning or reasoning capabilities of agents, emergent behaviour, interactions, social networks among others)

These difficulties should be taken into account not only when designing agent-based platforms with general broad purposes but also when improving the current tools that are nowadays in the market. Moreover, as social simulation field advances new features and needs will appear demanding for a reasonably fast adaptation of the current tools.

There are some issues that are not considered in the design of the software tools revised. First, in some areas of social sciences, such as archaeology, data used in specific case studies is often spatially referenced, and a need to track a huge volume of information arises. If the project is big enough a desktop computer or a small cluster can be insufficient to manage the amount of spatial information, being the result that some researches can be forced to decrease the quality and quantity of raw data managed by the simulation. Second, as social simulation advances, the need to model and simulate a large number of agents and interactions between them increases. In some specific cases, those interactions can be extremely large thus forcing the scientist to limit its number in order to execute the simulation in a standard computer. Although some of the existing ABM platforms try to fix these problems through the use of distributed systems, none of them is specifically designed for its execution in distributed supercomputers, probably the hardware architecture more suited to execute large-scale simulations (Rubio \& Cela, 2010). Actually, this issue is also pointed at (Greenough, 2010) as a future challenge which must be faced in order to make agent based models a mainstream computational science technology.

As we pointed before, there are differences in terminology among software tools. Railsback et al. (Railsback, Lytinen, \& Jackson, 2006) point out at some important differences to this respect between Mason, Netlogo, Repast and Swarm. Terminology differences can not only confuse the user of the platform but also they can lead to mistakes when working in multidisciplinary teams. Given that social simulation is a recognised multidisciplinary field, more attention should be paid to this issue. Probably the causes of using different terms in the field come from the same background difference of those who developed the software tool. Therefore, people working in social simulation should discuss and define each of these terms to avoid future misunderstandings among multidisciplinary teams and the whole social simulation community.

Agent-based models are being actively applied in many practical areas. The applications range from modelling adaptive behaviours and emergence of new ones in hunter-gathered prehistoric societies to understanding consumer behaviours in stock markets. The scope of the applications varies also from minimalist academic models meant to capture the most salient features of a 


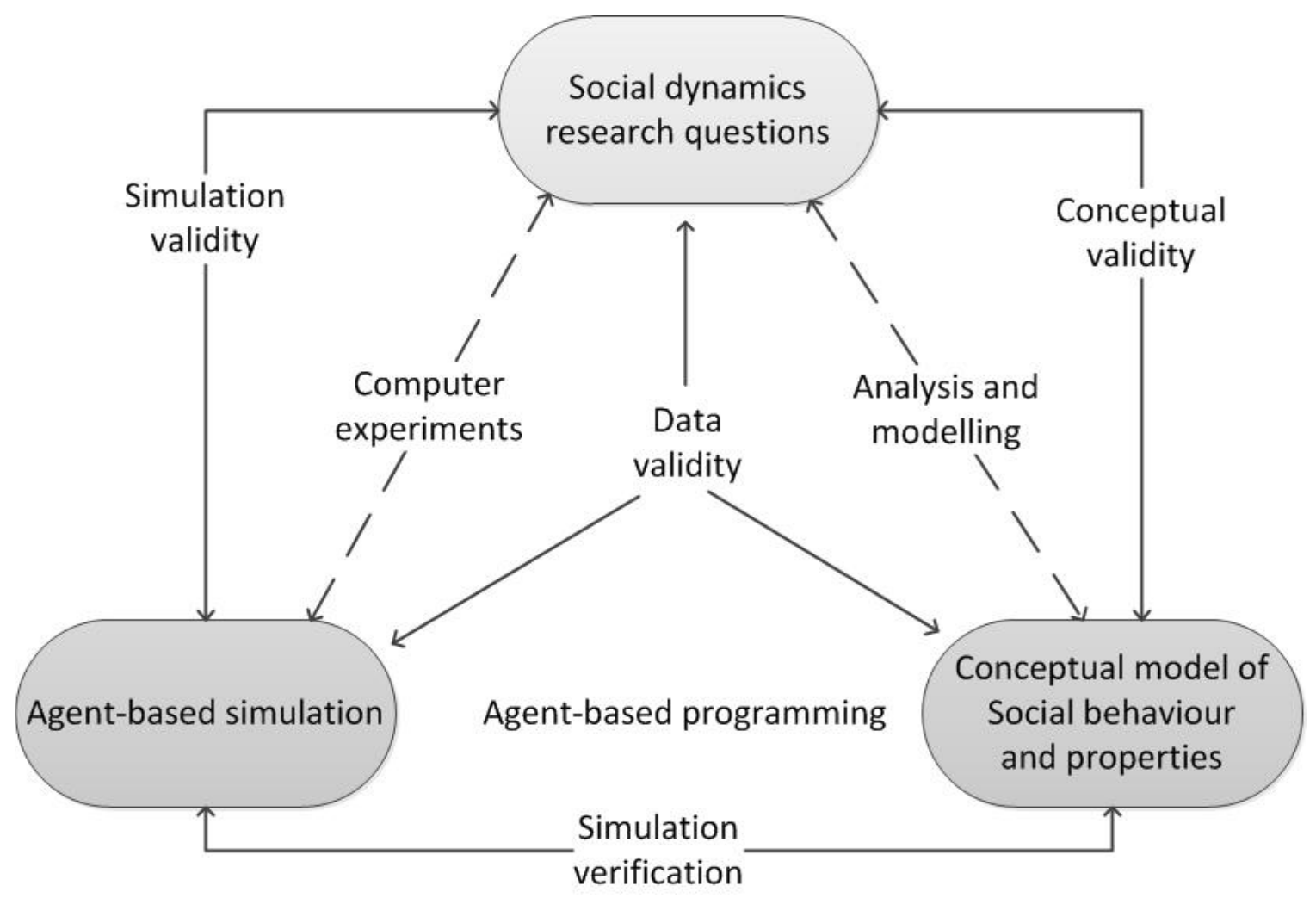

Figure 7. Validation and verification processes of the agent-based social model.

system to decision support systems that want to answer world policy questions, with the difficulty of including real data and later validating the model. According to Allan (Allan, 2010), in some areas of application is not clear that minimalist applications can be sufficient, although they might contribute to detect difficulties and shortage in the design of models. What is clear is that there is still a lot of work to do in social simulation field, not only in the technical aspect but also in terms of definition and agreement on models that emulate population dynamics. In that sense, Allan also points at the need of a new generation of agent-based models including more advanced aspects on communication networks, conditional neighbour interaction rules and a protocol for knowledge exchange.

\section{On verifying and validating models}

Validation and verification $(\mathrm{V} \& \mathrm{~V})$ is a significant element of any simulation study. As pointed by Robinson (Robinson, 1997), "without V \& V there are no grounds on which to place confidence in a (simulation) study's results". In simulation, we often differentiate between verification and validation. Verification is a process to determine whether a conceptual model has been implemented correctly in its computerized form. To borrow the computer programming term, we debug the model. Validation is a process to determine whether the model is an accurate representation of the system being studied for a given set of modelling objectives. A simplified version of 
agent-based simulation models of (Sargent, 2005) is shown in Figure 7. Moss (Moss, 2001) sees validation process as a a posteriori constraint and verification as a priori constraint. The reason is verification at the end limits the specification of the model, establishing some logic or theory limits before generating any output from simulation. However, validation aims to adjust the model (through simulation outputs) with observation. A failure on validating a verified model would imply to modify the model itself. As a consequence, either the model should be changed and separate somehow from the theory or formalism or this fact could indicate that the theory or formalism should be revised.

Although conceptually simple, verification can be challenging, especially when we are dealing with a relatively complex computer program. Law (Law, 2007) and Banks et al. (Banks, Carson, Nelson, \& Nicol, 1999) lists a number of techniques that can be used in a verification process. Validation is neither easy job. Actually, Robinson states that it is not possible to prove that a model is valid in all contexts, because a model is only a simplified version of reality. Consequently, a model cannot describe all aspects of a real system. Hence, the main objective of validation is to prove that a model is sufficiently accurate for parts of the real world under study. Indeed, one of the key aspects of validation is to assess whether the outcomes of a model can explain the real phenomenon that is being studied (Ormerod \& Rosewell, 2009). This can be fulfilled by performing as many validation methods as possible during a simulation study until we (and users) can gain enough confidence in the model and accept its results. Therefore, validation is a continuous process (Edmonds, 2000). Validation should also take into account the domain of the system under study (Sargent, 2005). Therefore, a validated model may not be valid for a set of different experimental conditions outside its domain.

Robinson identifies four different forms of validation in simulation modelling: conceptual model validation, data validation, white-box validation and black-box validation (Robinson, 1997). Conceptual model validation deals with issues such as the level of detail of the model and determines if it is enough for the purpose it was developed. Data validation is needed to determine whether the data used in the simulation study is sufficiently accurate. The black-box validation concerns with the relationship between inputs to the model and its outputs, ignoring the elements inside a model. The objective is to determine if the output of the model reflects the real world observation for the same set of inputs. Finally, white-box validation tries to answer the question does each element of the model and the structure of the model elements represent the real world with sufficient accuracy?

In the following subsections we will point at some specific issues of verification and validation processes in agent-based social models and the role of formal languages in these processes.

\section{Verifying and validating agent-based models}

In the area of agent-based simulation applied to social sciences and humanities validation is a big issue of concern. Despite the increasing popularity of agent-based simulation in the last two decades, validation techniques are neither as widely used nor as formalised as one would expect. According to the survey conducted by Heath et al. (Heath et al., 2009) on the articles related to agent-based models published between 1998 and 2008, 29\% of the articles did not discuss the validation of their models. They further divide the validation reported in the articles into two categories: conceptual (i.e. conceptual model validation) and operational (i.e. comparing the simulation result with the real observation). The researchers found that $17 \%$ of the articles used the conceptual validation only, 19\% used the operational validation only, and 35\% used both. They also noted the dominance of qualitative validation methods in the validation of agent-based models. They provide 
a conjecture that this issue might have its cause in the fact that many agent-based models are not conducive for quantitative validation methods.

Kennedy et al. (R. Kennedy, Xiang, Madey, \& Cosimano, 2006) suggest the lack of verification and validation for agent-based and social sciences could be attributed to agent-based modelling not being as mature as engineering modelling. Klügl noted that agent-based models often exhibit behaviour that can be problematic for validation purposes, such as non-linearities and multi-level properties (Klügl, 2008). In addition, agent-based models often use significantly more assumptions which make the assessment of the validity of these assumptions more difficult. Agent-based models also require the finer level of model detail in which data at that level of detail may be difficult to obtain.

Duong (Duong, 2010) also examines this issue and suggests that the greater uncertainty in social sciences compare to others, like physics simulations, the lack of consensus on how to represent social environment, and the lack of experimental controls in data collection might contribute to the difficulties in the validation of agent-based models. Windrum et al. (Windrum, Fagiolo, \& Moneta, 2007) examines a set of methodological problems in the empirical validation of agent-based models. The problems seem to have arisen due to, among other reasons, the lack of techniques to build and analyse these models and the lack of comparability between the ones which have already been developed.

A number of validation techniques have been proposed for agent-based simulation modelling. Klügl (Klügl, 2008) proposes a validation process for ABS models combining face validation and statistical methods. Arifin et al. in (Arifin, Davis, \& Zhou, 2011) explain there are three ways to validate an agent-based simulation:

1. Through comparison of simulation output with real phenomena. Although simple, this method has disadvantages when real data is not complete.

2. Constructing mathematical models of the system under study and compare these models with the simulation results. However, is not always possible to build a mathematical model of reality, specially when formulating complex systems.

3. The third technique is docking (also known as alignment, replication, cross-model validation, or model-to-model comparison), a process of comparing two similar models which address the same question or problem with the objective of not only finding their similarities and differences but also to gain understanding of the phenomenon under study (Burton, 1998). Performing this comparison between independent simulation tools, docking might find differences of interpretation in the model specification and also in the implementations. Nevertheless finding a similar behaviour among multiple simulations will increase the validation confidence. Some examples of docking can be found in the literature. We will point at docking of the beer distribution game (North \& Macal, 2002), of simulation of organisations (Ashworth \& Louie, 2002) and of collaboration network (Xu, Gao, \& Madey, 2003). (Axtell et al., 1996).

Another technique is the validation at two levels, called cross-validation (Moss \& Edmonds, 2003). It consists of a first qualitative validation at the agents' level, checking that the behaviour of the computational agents is similar to the target agents, and statistical validation of patterns of behaviour of the overall system. The concept of cross-validation comes from some ideas and theories from Physics, specially on looking at systems with high volatility, and the social theories of social embeddedness. 


\section{OVERVIEW ON AGENT-BASED SOCIAL MODELLING AND THE USE OF FORMAL LANGUAGES26}

\section{The use of formal languages in verification and validation}

The use of formal methods, widely extended in engineering and computer science, can help in verification process of social simulation. The reason is that formal specification of models requires the designer to clearly, concisely and unambiguously state what a system should do. The specification does not say how the model should do but what it does. In that way, the formalism specifies an abstract representation of the system under study. The ultimate goal is to validate this specification with experts from the domain of study (Black, Hall, Jones, Larson, \& Windley, 1996), who should say if the specification express what they want.

After an agreement has been set up, there is no ambiguity on what the simulation model should perform. Later, the programmer will translate the specification to the implementation. Unless there is an automatic method to do this translation from the formalism to the code, verification should be performed. However, if this automatic mechanism exists, the programmer will find it very helpful since one can take the formal language to verify that the code is performing as agreed.

In that sense, Moss et al. (Moss, Edmonds, \& Wallis, 1997) use a declarative formalism to address the validation and verification of $\mathrm{ABM}$ with cognitive agents. A similar approach is followed by Fonseca (Fonseca, 2008) who takes advantage of SDL to specify agent-based social models, as we mentioned in Section . Fonseca also develop an tool to design simulation models with SDL language that automatically translates SDL to an implementation code (Fonseca, 2010). As said, this has the advantage to allow users to skip verification process.

\section{Conclusions}

In this chapter, we have revised the concept and process of modelling in social science. We have seen why modelling is necessary in all disciplines of science and the characteristics of the modelling process. We focused our attention to the use of formal languages when modelling social systems. We saw the current alternatives that are being used in social fields and humanities, such as textual representation or the use of diagrams. The main drawback of describing a social system with natural language is its ambiguity. This issue has special significance when working in multidisciplinary teams or when trying to replicate models.

However, some advances have been made in social sciences. One example quite successful is the use of ODD protocol. Despite being ambiguous, it provides some ideas, concepts and organisation of models that have been very well accepted by practitioners (Grimm et al., 2010). But there is a long path to walk. Social sciences and humanities should profit from other available formal languages that are currently used in other applications of simulation to improve the description of their models. Perhaps increasing the interdisciplinary work in teams could advance this issue. Computer scientists are used to specify large complex systems through the use of mathematics, logical notation or specification languages. Social systems are perhaps more complex in terms of interaction, structure and emergent behaviour but nothing tell us it is not possible to go further, given the big advances made in the last 15 years. Formal languages can be the means to automatize the generation of computer code and to help in verification process.

There is also still a lot of work to do in verification and validation applied to social agentbased simulation. Ormerod and Bridget (Ormerod \& Rosewell, 2009) state that "no firm conclusions have been reached on the appropriate way to verify or validate such models ". The process of validation requires a clear view of what the model is trying to explain and with which goals. Therefore, as Ormerod and Rosewell state, we need to answer the question "What are the key facts that 


\section{OVERVIEW ON AGENT-BASED SOCIAL MODELLING AND THE USE OF FORMAL LANGUAGES27}

the model needs to explain and how well must it do it?". Later, validation will show if the model outcomes explain the phenomenon under study.

\section{References}

Albiero, F., Fitzek, F., \& Katz, M. (2007). Cooperative power saving strategies in wireless networks: an agent-based model. In 4th International Symposium on Wireless Communication Systems, ISWCS 2007 (pp. 287-291).

Allan, R. (2010). Survey of agent based modelling and simulation tools (Tech. Rep.). Computational Science and Engineering Department, STFC Daresbury Laboratory, Warrington WA4 4AD.

Altaweel, M., Alessa, L. N., \& Kliskey, A. D. (2010). Social influence and decision-making: Evaluating agent networks in village responses to change in freshwater. Journal of Artificial Societies and Social Simulation, 13(1), 15. Available from http://jasss.soc.surrey.ac.uk/13/1/15.html

Arifin, S., Davis, G., \& Zhou, Y. (2011). A spatial agent-based model of malaria: Model verification and effects of spatial heterogeneity. International Journal of Agent Technologies and Systems (IJATS), $3(3), 17-34$.

Ashworth, M. J., \& Louie, M. A. (2002). Alignment of the garbage can and nk fitness models: A virtual experiment in the simulation of organizations. Available from http://citeseerx.ist.psu .edu/viewdoc/summary?doi=10.1.1.86.6323

Aumann, R. (1985). What is game theory trying to accomplish? In K. Arrow \& S. Honkapohja (Eds.), Frontiers of economics.

Axelrod, R. (1997). Advancing the art of simulation in the social sciences. Complexity, 3(2), 16-22.

Axtell, R. (2000, November). Why agents?: on the varied motivations for agent computing in the social sciences (Tech. Rep. No. 17). The Brookings Institution, 1775 Massachusetts Ave. NW, Washington, DC 20036;: Center on Social and Economic Dynamics.

Axtell, R., Axelrod, R., Epstein, J., \& Cohen, M. (1996). Aligning simulation models: A case study and results. Computational and Mathematical Organization Theory, 1(2), 123-141.

Balbi, S., \& Giupponi, C. (2010). Agent-Based Modelling of Socio-Ecosystems: A Methodology for the Analysis of Adaptation to Climate Change. International Journal of Agent Technologies and Systems (IJATS), 2(4), 17-38.

Bankes, S. C. (2002). Agent-based modeling: A revolution? Proceedings of the National Academy of Sciences of the United States of America, 99(Suppl 3), 7199-7200. Available from http: //www .pnas.org/content/99/suppl.3/7199.short

Banks, J. (1998). Handbook of simulation: principles, methodology, advances, applications, and practice. Wiley-Interscience.

Banks, J., Carson, J., Nelson, B., \& Nicol, D. (1999). Discrete-event simulation. Prentice-Hall. (Chapter 10)

Barcelo, J. A., Cuesta, J. A., Del Castillo, F., Galan, J. M., Mameli, L., Quesada, M., et al. (2010). Patagonian ethnogenesis: towards a computational simulation approach. In Proceedings of the 3rd world congress on social simulation (pp. 1-9). Kassel, Germany.

Bedau, M. A. (2003). Artificial life: organization, adaptation and complexity from the bottom up. Trends in Cognitive Sciences, 7(11), 505 - 512. Available from http://www.sciencedirect.com/ science/article/pii/S1364661303002626

Bennett, D. S. (2008). Governments, civilians, and the evolution of insurgency: Modeling the early dynamics of insurgencies. Journal of Artificial Societies and Social Simulation, 11(4), 7. Available from http://jasss.soc.surrey.ac.uk/11/4/7.html

Bersini, H. (2012). UML for ABM. Journal of Artificial Societies and Social Simulation, 15(1), 9. Available from http://jasss.soc.surrey.ac.uk/15/1/9.html

Bigbee, A., Cioffi-Revilla, C., \& Luke, S. (2007). Replication of sugarscape using mason. Agent-Based Approaches in Economic and Social Complex Systems IV, 183-190. 


\section{OVERVIEW ON AGENT-BASED SOCIAL MODELLING AND THE USE OF FORMAL LANGUAGES28}

Black, P., Hall, K., Jones, M., Larson, T., \& Windley, P. (1996). A brief introduction to formal methods. In Proceedings of the ieee custom integrated circuits conference (pp. 377-380).

Box, P. (2002). Integrating geographic information systems and agent-based modeling techniques for simulating social and ecological processes. In H. Gimblett (Ed.), (pp. 59-82). Oxford University Press, USA.

Burmeister, B., Haddadi, A., \& Mattilys, G. (1997). Application of multi-agent sistems in traffic and transportation. In Software ingeneering ieee proceedings (Vol. 114, pp. 51-60).

Burton, R. (1998). Simulating organizations: Computational models of institutions and groups. In M. Prietula, K. Carley, \& L. Gasser (Eds.), (chap. Validating and docking: An overview, summary and challenge). Menlo Park, CA: AAAI Press.

Castle, C., \& Crooks, A. (2006). Principles and concepts of agent-based modelling for developing geospatial simulations. University College London, Working Paper Series, 110.

Chen, D., Theodoropoulos, G., Turner, S., Cai, W., Minson, R., \& Zhang, Y. (2008, July). Large scale agent-based simulation on the grid. Future Generation Computer Systems, 24(7), 658-671.

Cioffi-Revilla, C. (2010). A methodology for complex social simulations. Journal of Artificial Societies and Social Simulation, 13(1), 7. Available from http://jasss.soc.surrey.ac.uk/13/1/ 7.html

Cioffi-Revilla, C., Rogers, J. D., \& Latek, M. (2010). The mason householdworlds of pastoral nomad societies. In C. C.-R. K. Takadama \& G. Deffaunt (Eds.), Simulating interacting agents and social phenomena: The second world congress in social simulation. Berlin and Tokyo: Springer.

Collier, N. (2001). Repast: An extensible framework for agent simulation. Natural Resources and Environmental Issues, 8(1), 4.

Damaceanu, R.-C. (2008). An agent-based computational study of wealth distribution in function of resource growth interval using netlogo. Applied Mathematics and Computation, 201(1-2), 371-377. Available from http://www.sciencedirect.com/science/article/pii/ S0096300307012143

Davies, R., Roderick, P., \& Raftery, J. (2003). The evaluation of disease prevention and treatment using simulation models. European Journal of Operational Research, 150(1), 53-66.

Dean, J., Gumerman, G., Epstein, J., Axtell, R., Swedlund, A., Parker, M., et al. (2000). Understanding anasazi culture change through agent-based modeling. Dynamics in human and primate societies: Agent-based modeling of social and spatial processes, 179-205.

Dunham, J. B. (2005). An agent-based spatially explicit epidemiological model in mason. Journal of Artificial Societies and Social Simulation, 9(1), 3. Available from http:// jasss.soc. surrey.ac.uk/ 9/1/3.html

Duong, D. (2010). Verification, Validation, and Accreditation (VV\&A) of Social Simulations. In Spring simulation interoperability workshop, orlando, april 12-16 2010.

Edmonds, B. (2000). The use of models - making MABS more informative. In Second international workshop, mabs 2000 (pp. 15-31). SpringerVerlag.

Edmonds, B. (2006). The emergence of symbiotic groups resulting from skill-differentiation and tags. Journal of Artificial Societies and Social Simulation, 9(1), 10. Available from http: // jass . soc . surrey.ac.uk/9/1/10.html

El Hadouaj, S., Drogoul, A., \& Espié, S. (2001). How to combine reactivity and anticipation: the case of conflicts resolution in a simulated road traffic. Multi-Agent-Based Simulation, 157-167.

Epstein, G., \& Gang, I. (2006). The Influence of Others on Migration Plans. Review of Development Economics, 10(4), 652-665.

Epstein, J. (2008). Why model? Journal of Artificial Societies and Social Simulation, 11(4), 12. Available from http://jasss.soc.surrey.ac.uk/11/4/12.html

Epstein, J., \& Axtell, R. (1996). Growing artificial societies: social science from the bottom up. The MIT Press.

Fonseca, P. (2008). SDL, a graphical language useful to describe social simulation models. Proceedings of the 2nd Workshop on Social Simulation and Artificial Societies Analysis (SSASA'08). 


\section{OVERVIEW ON AGENT-BASED SOCIAL MODELLING AND THE USE OF FORMAL LANGUAGES29}

Fonseca, P. (2010). Using Specification and Description Language to define and implement discrete simulation models. In Summer simulation multiconference, ottawa. Available from http:// hol. handle.net/2117/8341

Fonseca, P., Casanovas, J., Monero, J., \& Guasch, A. (2011, July). Experiences of simulation use in industrial projects. In SCS M\&S Magazine.

Fowler, M., \& Scott, K. (2000). Uml distilled: a brief guide to the standard object modeling language (2nd ed.). Boston, MA, USA: Addison-Wesley Longman Publishing Co., Inc. (ISBN 0-201-65783-X)

Gardner, M. (1970). Mathematical games: The fantastic combinations of john conway's new solitaire game 'life'. Scientific American, 223(4), 120-123.

Gilbert, G. (2008). Agent-based models. Sage Publications, Inc.

Gilbert, G., \& Troitzsch, K. (2005). Simulation for the social scientist. Open Univ Pr.

Gilbert, N., \& Bankes, S. (2002). Platforms and methods for agent-based modeling. Proceedings of the National Academy of Sciences of the United States of America, 99(Suppl 3), 7197-7198. Available from http://www.pnas.org/content/99/suppl.3/7197. short

Goodchild, M. (2005). Gis, spatial analysis, and modeling. In D. Maguire, M. Batty, \& M. Goodchild (Eds.), (chap. GIS and Modeling Overview). Redlands, California: Esri Press.

Gratch, J., \& Marsella, S. (2001). Tears and fears: Modeling emotions and emotional behaviors in synthetic agents. In Proceedings of the fifth international conference on autonomous agents (pp. 278-285).

Greenough, C. (2010, October). Proposal to establish a uk collaborative computational project in abms.

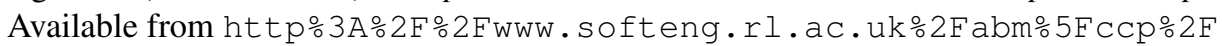

Grimm, V., Berger, U., Bastiansen, F., Eliassen, S., Ginot, V., Giske, J., et al. (2006). A standard protocol for describing individual-based and agent-based models. Ecological modelling, 198(1-2), 115-126.

Grimm, V., Bergerb, U., DeAngelisc, D. L., Polhill, J. G., Giskee, J., \& Railsback, S. F. (2010). The odd protocol: A review and first update. Ecological Modelling, 221, 2760-2768.

Hailegiorgis, A., Kennedy, W., Rouleau, M., Bassett, J., Coletti, M., Balan, G., et al. (2010). An agent based model of climate change and conflict among pastoralists in east africa. In D. A. Swayne, W. Yang, A. A. Voinov, A. Rizzoli, \& T. Filatova (Eds.), Proceedings of the international congress on environmental modeling and software (iemss2010). Ottawa, Ontario, Canada.

Hanneman, R. (1988). Computer-assisted theory building: Modeling dynamic social systems. Newbury Park, CA: Sage.

Harvey, B. (1997). Computer science logo style: Symbolic computing (2nd ed., Vol. 1-3). MIT Press.

Heath, B., Hill, R., \& Ciarallo, F. (2009). A survey of agent-based modeling practices (january 1998 to july 2008). Journal of Artificial Societies and Social Simulation, 12(4), 9.

Huhns, M., \& Singh, M. (1997). Readings in agents. Morgan Kaufmann Publishers Inc.

Janssen, M., Alessa, L., Barton, M., Bergin, S., \& Lee, A. (2008). Towards a community framework for agent-based modelling. Journal of Artificial Societies and Social Simulation, 11(2), 6.

Janssen, M. A. (2009). Understanding artificial anasazi. Journal of Artificial Societies and Social Simulation, 12(4), 13. Available from http:// jasss.soc.surrey.ac.uk/12/4/13.html

Kennedy, R., Xiang, X., Madey, G., \& Cosimano, T. (2006). Verification and validation of scientific and economic models. In Proceedings of agent 2005: Generative social processes, models, and mechanisms (pp. 177-192). Chicago. Argonne National Laboratory: Citeseer.

Kennedy, W., Hailegiorgis, A., Rouleau, M., Bassett, J., Coletti, M., Balan, G., et al. (2010). An agent-based model of conflict in east africa and the effect of watering holes. In Proceedings of the 19th conference on behavior representation in modeling and simulation (brims). columbia, south carolina.

Klügl, F. (2008). A Validation Methodology for Agent-Based Simulations [Proceedings Paper]. In Proceedings of the 23rd Annual ACM Sysmposium on Applied Computing (p. 39-43). 1515 BROADWAY, NEW YORK, NY 10036-9998 USA: ASSOC COMPUTING MACHINERY. (23rd Annual ACM Symposium on Applied Computing, Fortaleza, BRAZIL, MAR 16-20, 2008)

Köhler, M., Langer, R., Lüde, R. von, Moldt, D., Rölke, H., \& Valk, R. (2007). Socionic multi-agent systems based on reflexive petri nets and theories of social self-organisation. Journal of Artificial Societies 


\section{OVERVIEW ON AGENT-BASED SOCIAL MODELLING AND THE USE OF FORMAL LANGUAGES30}

and Social Simulation, 10(1), 3. Available from http://jasss.soc. surrey.ac.uk/10/1/ 3. html

Kohler, T., \& Leeuw, S. van der. (2007). The model-based archaeology of socionatural systems. Santa Fe, New Mexico: SAR Press.

Koper, R. (2005). Increasing learner retention in a simulated learning network using indirect social interaction. Journal of Artificial Societies and Social Simulation, 8(2).

Law, A. M. (2007). Simulation modeling and analysis (4th ed.). Mcgraw-Hill series in industrial engineering and management science.

Leeuw, S. van der. (2004). Why model? Cybernetics and Systems, 35(2-3), 117-128.

Leiva Olmos, J., Fonseca, P., \& Ocaña, J. (2011). Modelling surgical pavilions and a unit of anaesthesia on a chilean hospital using specification and description language. In Actas de la xiii conferencia española y iii encuentro iberoamericano de biometría.

Leombruni, R., \& Richiardi, M. (2006). Laborsim: An agent-based microsimulation of labour supply-an application to italy. Computational Economics, 27(1), 63-88.

Lin, F., \& Pai, Y. (2000). Using multi-agent simulation and learning to design new business processes. Systems, Man and Cybernetics, Part A: Systems and Humans, IEEE Transactions on, 30(3), 380-384.

Lingnau, A., \& Drobnik, O. (1999). Simulating mobile agent systems with swarm. In Agent systems and applications, 1999 and third international symposium on mobile agents. proceedings. first international symposium on (pp. 272-273).

List of abm tools. (n.d.). Available from http: / / www2 econ. iastate. edu/tesfatsi/acecode . htm

Lozares Colina, C. (2004). La simulación social, ¿una nueva manera de investigar en ciencia social? Papers: revista de sociologia(72), 165-188.

Luke, S., Cioffi-Revilla, C., Panait, L., Sullivan, K., \& Balan, G. (2005). Mason: A multiagent simulation environment. Simulation, 81(7), 517.

Luke, S., \& Ziparo, V. (2010). Learn to behave! rapid training of behavior automata. In Proceedings of adaptive and learning agents workshop at aamas (pp. 61-68).

Luna, F., \& Stefansson, B. (2000). Economic simulations in swarm: Agent-based modelling and object oriented programming (Vol. 14). Springer.

Madey, G., Freeh, V., \& Tynan, R. (2002). Agent-based modeling of open source using swarm. In Americas Conference on Information Systems (AMCIS2002) (pp. 1472-1475). Dallas, TX, USA.

Madhavan, P., Papelis, Y., Kady, R., \& Moya, L. (2009). An agent-based model of crowd cognition. In Proceedings of the 18th conference on behavior representation in modeling and simulation (pp. 139140).

Menéndez, M., \& Collado, S. (2007). Simulación de procesos sociales basada en agentes software. EMPIRIA. Revista de Metodología de Ciencias Sociales, 14, 139-161.

Michalski, R., Carbonell, J., \& Mitchell, T. (1985). Machine learning: An artificial intelligence approach (Vol. 1). Morgan Kaufmann.

Millington, J., Romero-Calcerrada, R., Wainwright, J., \& Perry, G. (2008). An agent-based model of mediterranean agricultural land-use/cover change for examining wildfire risk. Journal of Artificial Societies and Social Simulation, 11(4), 4. Available from http://jasss.soc.surrey.ac.uk/11/4/ 4. html

Minar, N., Burkhart, R., Langton, C., \& Askenazi, M. (1996). The swarm simulation system: A toolkit for building multi-agent simulations (Working Papers No. 96-06-042). Santa Fe Institute.

Moss, S. (2001). Messy systems - the target for multi agent based simulation. In S. Moss \& P. Davidsson (Eds.), Multi-agent-based simulation (Vol. 1979, p. 1-14). Springer Berlin / Heidelberg.

Moss, S., \& Edmonds, B. (2003). Sociology and simulation: Statistical and qualitative crossvalidation (Tech. Rep. No. 03105). Available from http: / / cfpm. org/cpmrep105.html

Moss, S., Edmonds, B., \& Wallis, S. (1997, July). Validation and Verification of Computational Models with Multiple Cognitive Agents (Discussion Papers No. 97-25). Manchester Metropolitan University, 


\section{OVERVIEW ON AGENT-BASED SOCIAL MODELLING AND THE USE OF FORMAL LANGUAGES31}

Centre for Policy Modelling. Available from http://ideas.repec.org/p/wuk/mcpmdp/ 9725.html

Nance, R. (1994). The conical methodology and the evolution of simulation model development. Annals of Operations Research, 53(1), 1-45.

Nikolai, C., \& Madey, G. (2009). Tools of the trade: A survey of various agent based modeling platforms. Journal of Artificial Societies and Social Simulation, 12(2), 2. Available from http:// jass . soc . surrey.ac.uk/12/2/2.html

Nikolai, C., \& Madey, G. (2011, August). Comparison of agent-based modelling software. Available from http://en.wikipedia.org/wiki/Comparison_of_agent-based _modeling_software

North, M., Collier, N., \& Vos, J. (2006). Experiences creating three implementations of the repast agent modeling toolkit. ACM Transactions on Modeling and Computer Simulation (TOMACS), 16(1), 125.

North, M., \& Macal, C. (2002). The beer dock: Three and a half implementations of the beer distribution game. In Swarmfest 2002.

North, M., \& Macal, C. (2005). Artificial life models in software. In M. Komosinski (Ed.), (pp. 115-141). Heidelberg, Germany: Springer.

Onggo, B. (2010). Conceptual modelling for discrete-event simulation. In R. Brooks, S. Robinson, K. Kotiadis, \& D.-J. van der Zee (Eds.), (pp. 337-354). Abingdon: Taylor \& Francis.

Orcutt, G. (1957). A new type of socio-economic system. The Review of Economics and Statistics, 39(2), $116-123$.

Ormerod, P., \& Rosewell, B. (2009). Validation and Verification of Agent-Based Models in the Social Sciences [Proceedings Paper]. In Squazzoni, F (Ed.), Epistemilogical Aspects of Comuter Simulation in the Social Sciences, Second International Workshop, EPOS 2006 (Vol. 5466, p. 130-140). Heidelberger Platz 3, D-14197 Berlin, Germany: Springer-Verlag. (2nd International Workshop on Epistemological Perspectives on Simulation, Brescia, Italy, oct 05-06, 2006)

Pavon, J., Arroyo, M., Hassan, S., \& Sansores, C. (2008). Agent-based modelling and simulation for the analysis of social patterns. Pattern Recognition Letters, 29(8), 1039-1048.

Pidd, M. (2003). Tools for Thinking: Modelling in Management Science (2nd ed.). Chichester, UK: Wiley.

Pidd, M. (2010). Why modelling and model use matter. Journal of the Operational Research Society, 61(1), $14-24$.

Polhill, J. G., Parker, D., Brown, D., \& Grimm, V. (2008). Using the odd protocol for describing three agent-based social simulation models of land-use change. Journal of Artificial Societies and Social Simulation, 11(2), 3. Available from http://jasss.soc.surrey.ac.uk/11/2/3.html

Railsback, S., Lytinen, S., \& Jackson, S. (2006). Agent-based simulation platforms: Review and development recommendations. Simulation, 82(9), 609-623.

Resnick, M. (1994). Turtles, Termites and Traffic Jams: Explorations in Massively Parallel Microworlds. MIT Press.

Richiardi, M., Leombruni, R., Saam, N. J., \& Sonnessa, M. (2006). A common protocol for agent-based social simulation. Journal of Artificial Societies and Social Simulation, 9(1), 15. Available from http://jasss.soc.surrey.ac.uk/9/1/15.html

Robinson, S. (1997). Simulation model verification and validation: increasing the users' confidence. In Proceedings of the 29th conference on winter simulation (pp. 53-59).

Robinson, S. (2008). Conceptual modelling for simulation part i: definition and requirements. Journal of the Operational Research Society, 59(3), 278-290.

Robinson, S., \& Pidd, M. (1998). Provider and customer expectations of successful simulation projects. Journal of the Operational Research Society, 49(3), 200-209.

Rossiter, S., Noble, J., \& Bell, K. R. (2010). Social simulations: Improving interdisciplinary understanding of scientific positioning and validity. Journal of Artificial Societies and Social Simulation, 13(10), 1. Available from http://jasss.soc.surrey.ac.uk/13/1/10.html

Rouleau, M., Coletti, M., Bassett, J., Hailegiorgis, A., Gulden, T., \& Kennedy, W. (2009). Conflict in complex 


\section{OVERVIEW ON AGENT-BASED SOCIAL MODELLING AND THE USE OF FORMAL LANGUAGES32}

socio-natural systems: Using agent-based modeling to understand the behavioral roots of social unrest within the mandera triangle. In Proceedings of the human behavior-computational modeling and interoperability conference.

Roussopoulos, N., \& Karagiannis, D. (2009). Conceptual modeling: Past, present and the continuum of the future. In A. Borgida, V. Chaudhri, P. Giorgini, \& E. Yu (Eds.), Conceptual modeling: Foundations and applications (Vol. 5600, p. 139-152). Springer Berlin / Heidelberg.

Rubio, X. (2009). Modelització i simulació aplicades a la recerca i interpretació de camps de batalla. Unpublished doctoral dissertation, Universitat de Barcelona. Departament de Didàctica de les Ciències Socials, Barcelona, Spain. Available from http://hdl . handle. net/10803/1339

Rubio, X., \& Cela, J. (2010, April). Large-scale agent-based simulation in archaeology: an approach using high-performance computing. In Computer applications in archaeology. Granada, Spain.

Russell, S., \& Norvig, P. (2010). Artificial intelligence: a modern approach. Prentice hall.

Sargent, R. (2005). Verification and validation of simulation models. In Proceedings of the 37th winter simulation conference (pp. 130-143).

Schelling, T. (1971). Dynamic models of segregation. Journal of mathematical sociology, 1(2), 143-186.

Schlosser, A., Voss, M., \& Brückner, L. (2005). On the simulation of global reputation systems. Journal of Artificial Societies and Social Simulation, 9(1), 4. Available from http:// jasss.soc.surrey .ac.uk/9/1/4.html

Serenko, A., \& B., D. (2002). Agent toolkits: A general overview of the market and an assessment of instructor satisfaction with utilizing toolkits in the classroom (Working Paper (available at http://foba.lakeheadu.ca/serenko/) No. 455). Hamilton, OntariO: Michael G. DeGroote School of Business, McMaster University.

Shannon, R. (1976). Simulation modeling and methodology. In Proceedings of the 76 bicentennial conference on winter simulation (pp. 9-15).

Starlogot. (n.d.). Available from http: / / ccl. northwestern. edu/cm/starlogot/

Sterman, J. (2000). Business dynamics: Systems thinking and modelin for a complex world. Mcgraw-Hill Higher Education.

Stewart, I. (1990). Does god play dice? Penguin Books.

Strader, T., Lin, F., \& Shaw, M. (1998). Simulation of order fulfillment in divergent assembly supply chains. Journal of Artificial Societies and Social Simulation, 1(2), 36-37.

Swarm development group. (n.d.). Available from http: //www. swarm.org/

Terna, P. (1998). Simulation tools for social scientists: Building agent based models with swarm. Journal of Artificial Societies and Social Simulation, 1(2), 1-12.

Tesfatsion, L. (2002). Agent-based computational economics: Growing economies from the bottom up. Artificial life, 8(1), 55-82.

Tesfatsion, L. (2006). Handbook of computational economics: Agent-based computational economics. In L. Tesfatsion \& K. Judd (Eds.), (p. 831-880). North-Holland, Amsterdam, The Netherlands.

Tisue, S., \& Wilensky, U. (2004). Netlogo: A simple environment for modeling complexity. In International conference on complex systems (pp. 16-21).

Tobias, R., \& Hofmann, C. (2004). Evaluation of free java-libraries for social-scientific agent based simulation. Journal of Artificial Societies and Social Simulation, 7(1).

Troitzsch, K. (1997). Lecture notes in economics and mathematical systems. In R. Conte, H. R., \& P. Terna (Eds.), (Vol. 456, chap. Social science simulation - origins, prospects, purposes). Berlin, Germany: Springer- Verlag.

Vidgen, R., \& Padget, J. (2009). Sendero: An extended, agent-based implementation of kauffmanś nkcs model. Journal of Artificial Societies and Social Simulation, 12(4), 8. Available from http:// jasss.soc.surrey.ac.uk/12/4/8.html

Villatoro, D., \& Sabater-Mir, J. (2008). Mechanisms for social norms support in virtual societies. In Proceedings of the 5th conference of the european social simulation association (essa08).

Von Neumann, J. (1966). Theory of self-reproducing automata (A. Burks, Ed.). Urbana, IL.: University of Illinois Press. 
OVERVIEW ON AGENT-BASED SOCIAL MODELLING AND THE USE OF FORMAL LANGUAGES33

Wasserman, S. (1994). Social network analysis: Methods and applications. Cambridge university press.

Wegener, M. (2000). Spatial models and gis: New potential and new models. In A. Fotheringham \& M. Wegener (Eds.), (chap. Spatial models and GIS). London: Taylor \& Francis.

Weiss, G. (1999). Multiagent systems: a modern approach to distributed artificial intelligence. The MIT press.

Wheatley, D., \& Gillings, M. (2000). Vision, perception and gis: developing enriched approaches to the study of archaeological visibility. Beyond the map: archaeology and spatial technologies, 1-27.

Wierzbicki, A., \& Nielek, R. (2011). Fairness emergence in reputation systems. Journal of Artificial Societies and Social Simulation, 14(1), 3. Available from http://jasss.soc.surrey.ac.uk/14/1/ 3. html

Wilensky, U. (2002). Modeling nature's emergent patterns with multi-agent languages. In Proceedings of eurologo (pp. 1-6).

Windrum, P., Fagiolo, G., \& Moneta, A. (2007). Empirical Validation of Agent-Based Models: Alternatives and Prospects [Article]. Journal of Artificial Societies and Social Simulation, 10(2), 8. Available from http://jasss.soc.surrey.ac.uk/10/2/8.html

Xu, J., Gao, Y., \& Madey, G. (2003). A docking experiment: Swarm and repast for social network modeling. In Seventh annual swarm researchers meeting (swarm2003).

Yang, L., \& Gilbert, N. (2008). Getting away from numbers: Using qualitative observation for agent-based modeling. Advances in Complex Systems, 11(2), 175-186.

Zhao, H., \& Li, X. (2008). H-trust: A robust and lightweight group reputation system for peer-to-peer desktop grid. In The 28th international conference on distributed computing systems workshops (pp. 235-240). 